This item was submitted to Loughborough's Research Repository by the author.

Items in Figshare are protected by copyright, with all rights reserved, unless otherwise indicated.

\title{
The role of term spread and pattern changes in predicting stock returns and volatility of the United Kingdom: Evidence from a nonparametric causality-in- quantiles test using over 250 years of data
}

\section{PLEASE CITE THE PUBLISHED VERSION}

https://doi.org/10.1016/j.najef.2018.05.006

\section{PUBLISHER}

(C) Elsevier

\section{VERSION}

AM (Accepted Manuscript)

\section{PUBLISHER STATEMENT}

This work is made available according to the conditions of the Creative Commons Attribution-NonCommercialNoDerivatives 4.0 International (CC BY-NC-ND 4.0) licence. Full details of this licence are available at: https://creativecommons.org/licenses/by-nc-nd/4.0/

\section{LICENCE}

CC BY-NC-ND 4.0

\section{REPOSITORY RECORD}

Gupta, Rangan, Marian Risse, David A. Volkman, and Mark E. Wohar. 2019. "The Role of Term Spread and Pattern Changes in Predicting Stock Returns and Volatility of the United Kingdom: Evidence from a Nonparametric Causality-in-quantiles Test Using over 250 Years of Data". figshare.

https://hdl.handle.net/2134/34988. 


\section{The Role of Term Spread and Pattern Changes in Predicting Stock Returns and Volatility of the United Kingdom: Evidence from a Nonparametric Causality-in- Quantiles Test Using Over 250 Years of Data}

\section{INTRODUCTION}

The relations among stock market returns, economic growth, and the slope of the term structure of interest rates are the subject of much research (e.g., see Chen, Roll and Ross 1986; Campbell 1987; Harvey 1989 for the early work in this area). Wheelock and Wohar (2009) offer a comprehensive literature survey on the usefulness of the term spread for predicting changes in economic activity. There is also an area of literature that investigates whether the yield spread is a leading indicator of stock returns. There are many studies (e.g., see Boudoukh et al 1993; Ostdiek 1998; McCown 1999, 2001; Resnick and Shoesmith 2002; Nyberg 2013; Fernandez-Perez et al., 2014) which report that the ex-ante equity risk premium is negative in periods preceded by an inverted yield curve.

In earlier work, Fama and French (1989) report that excess returns on US stocks and corporate bonds are positively related to the slope of the yield curve of US Treasury securities. They argue that the yield curve has predictive power because it is a proxy for discount rate shocks and both, stocks and long-term bonds, are long-term investments, and are highly susceptible to changes in investors' intertemporal discount rates. The large differences in the conditional risk premiums signaled by an upward-sloping or inverted yield curves may be due in part to differences in the volatility of the stock returns. Research related to this finds that in many cases, the volatility of the returns are much higher when the yield curves are upward-sloping, compared to when they are inverted.

The findings of recent work by Volkman et al., (2014), using US data, concurs with previous research that find a positive significant relation between conditional term spread and future equity returns and risk premia. However, explanatory power and robustness of the term spread is enhanced by including a vector of qualitative variables that proxy changes in the shape of the yield curve. Volkman et al., (2014) find the greatest economic gain occurs with a shift down in the yield curve accompanied by a steep conditional term spread. Volkman et al., (2014) also find any decrease in the long-term rate, pivot clockwise and rotation long down patterns result in significant positive subsequent 6 -month equity returns, especially in extreme economies. ${ }^{1}$ In the

\footnotetext{
${ }^{1}$ These equity returns are complemented by a positive influence of the term spread. Similar results were obtained at the sectoral level by Volkman et al., (2012).
} 
process, Volkman et al., (2014) connect to the burgeoning literature that studies whether components of yield curve incorporate any important information about future evolution in macroeconomic aggregates (see Ang et al., 2006; Diebold et al., 2006; Ferreira et al., 2008; Moench, 2012, among others).

Overall, the above literature highlights the importance of modelling changes in the shape of the yield curve when looking into the relation between equity returns and interest rate models. Uncovering the empirics of conditional influence of the changes in shape of the yield curve on economic growth and equity returns is important both from an academic as well as practitioner point of view.

Against the backdrop of the above research, the objective of our paper is to assess the predictive ability of changes in the shape of the yield curve (patterns) for excess stock returns and its volatility for the UK, the US and South Africa. We achieve this goal by using a nonparametric causalityin-quantiles test that has been recently developed by Balcilar et al. (2016), applied to over 250 years of monthly data for the UK covering the period 1753:08 to 2017:02. We also draw comparisons with historical data for a developed country, i.e., the US over the period 1871:02 to 2017:02 (to compare our results with that of Volkman et al., 2014), and an emerging market economy, namely South Africa, over the period 1936:01 to 2017:02. To the best of our knowledge, this is the first attempt to use historical data for developed and emerging market economies in predicting the conditional distributions of equity premium and its volatility based on changes in the shape of the yield curve.

The use of the nonparametric causality-in-quantiles test studies higher order causality over the entire conditional distribution and is inherently based on a nonlinear dependence structure between the variables of interest. Balcilar et al., (2016) essentially combines the causality-in-quantile test of Jeong et al. (2012) and the higher-moment $k^{\text {th }}$-order nonparametric causality of Nishiyama et al. (2011). The main novelties of this econometric framework and, thus, the empirical results of our paper are as follows: First, our estimation is robust to misspecification errors, as it detects the underlying dependence structure between the examined dependent variable (i.e., excess stock returns) vis-à-vis the predictors (i.e., term-spread, its patterns, and interaction between the term spread and the patterns (interaction)). In our empirical exercise, we show that this is particularly important given that excess returns is in fact related nonlinearly with its predictors, which in turn, validates the large literature that financial markets data tend to display nonlinear dynamics with respect to its predictors (Bekiros et al., 2016). Second, this methodology allows us to test not only 
for causality-in-mean (i.e. the first moment), but also for causality in the tails of the joint distribution of the variables. Our analysis reveals that this aspect is especially relevant in the light of the fact that the unconditional distribution of the dependent variable - i.e. excess stock returns - tends to exhibit fat tails; specifically, a heavy left tail. Thus, the nonparametric causality-inquantiles test allows us to capture bear, normal and bull market phases corresponding to the lower quantiles, the median, and the upper quantiles of the distribution, respectively. Third, we are also able to investigate causality-in-variance and, thus, study higher-order dependency. This again is highly pertinent since, during some periods, causality in the conditional-mean may not exist, while at the same time higher-order interdependencies may turn out to be significant. Given these advantages of the chosen approach, our paper can be considered to be an extension of the work of Volkman et al. (2014), which used a linear model, possibly subject to misspecification due to nonlinearity, and restricted to only studying returns and not volatility, and that too only at the conditional mean, rather than the entire conditional distribution of both returns and volatility.

Note that, nonlinear causality tests (for example, Hiemstra and Jones (1994), and Diks and Panchenko (2005, 2006), Bai et al., (2010, 2011)) and GARCH models could have been used to analyze the impact of term-spread, its patterns and interaction on excess stock returns and/or volatility, but these approaches would rely on conditional-mean based estimation, and hence fail to capture the entire conditional distribution of excess stock returns and volatility - something we can do with our approach. In the process, our test is a more general procedure of detecting causality in both returns and volatility simultaneously at each point of their respective conditional distributions. Hence, we are able to capture existence or non-existence of causality at various phases of the stock markets, as pointed out above. Being a more general test, our method is more likely to pick up causality when conditional mean-based tests might fail to do so. In addition, since we do not need to decide on the number of regimes as in a Markov-switching model, and can test for causality at each point of the conditional distribution characterizing specific regimes, our test also does not suffer from any misspecification in terms of specifying and testing for the optimal the number of regimes.

The rest of the paper is organized as follows: Section 2 discusses the theory of pattern changes, with Section 3 presenting the data. Section 4 describes the higher-moment nonparametric quantile causality test, while Section 5 discusses the main results along with robustness tests. Finally, Section 6 concludes. 


\section{Theory Of PatTERN Changes}

Previous researchers have found and demonstrated a strong relation between interest rates and economic activity and, similarly, ex ante equity returns. Most researchers have focused on a country's monetary policy and subsequent adjustment to the short rate by their governing bodies implicitly assuming a static long rate while other researchers assumed a constant relation between the short and long rates such as previous yield curve and term spread studies. However, simple observation of the interaction between short and long rates reveals a non-constant and irregular relation between short and long rates. Previous research assumed short and long rates move in the same direction and by similar incremental changes, however, we assert that short and long rates will react differently and by different degrees of incremental changes to the same economic event. Long rates do not always behave predictably given corresponding changes in short term rates. We note that the relation between monetary policy, business conditions, and future equity returns is complicated and assert that changes in the yield curve contains information about key economic factors affecting the economy not present in static term spread or short rates.

Employing the Expectation Theory of Interest Rates, we illustrate the varying relation between interest rates, why long rates and short rates may react differently to the same economic news and why different spread patterns may have dissimilar effects on future equity returns. The Expectation Theory assumes that long rates are a product of the short rate and the long forward rate and that long rates contain two elements: information about financial market expectation of monetary policy over the duration of the investment and compensation for inflation risk premia. Therefore, long rates may change by different degrees based on the current state of the general economy and investors' varying views of future Fed policies, economic activity, and inflation expectations.

The Expectation Theory states that the market sets long-term yields equal to a weighted average of the short term rate and expected future spot rates. Future spot rates are a function of investor's expectation of future inflation, economic activity and government policies.

$1+L R_{t, n}=\prod_{j=0}^{n x m} E_{t}\left(1+R_{t+m \times j, m} \mid I_{t}\right)$

Separating the current known short term rate we get:

$1+L R_{t, n}=\left(1+S R_{t, m}\right) \prod_{j=1}^{n \times m} E_{t}\left(1+R_{t+m \times j, m} \mid I(t)\right)$ 
where $L R_{t, n}$ is the current long rate with a holding horizon of $n, R_{t^{+} m x ;, m}$ is future spot rates with holding periods of $m, S R_{t, m}$ is the current short rate with a short holding horizon of $m$, and $E_{t}$ is the usual expectations operator based on information set $I_{t}$.

Extending Equation 1 one period (opm) into the future, we get the expected spot rate of $t+1$ :

$1+E_{t}\left(L R_{t+m, n-m}\right)=\prod_{j=1}^{n \times m} E_{t}\left(1+R_{t+m \times j, m} \mid I_{t+1}\right)$

Substituting Equation 3 into Equation 2 we get the current relation between the current long spot rate, $L R_{t, n}$, the current spot short rate, $S R_{t, n}$, and the expected future long spot rate, $E_{t}\left(L R_{t+m, n-m n}\right.$ $\left.I_{t}\right)$ :

$$
1+L R_{t, n}=\left(1+S R_{t, m}\right)\left(1+E_{t}\left(L R_{t+m, n-m}\right)\right)
$$

As Equation 4 illustrates, the long spot rate is a function of both the short rate and expectation of future rates. Therefore, the long rate could increase (decrease) as the short rate increases (decreases) or change because of perceived changes to future economic environments and/or inflationary expectations.

We model the irregular interactions between interest rates and their effect on ex ante equity returns by assuming the relation between rates and their effects on equity returns is not static and by adopting a dynamic yield curve in our analysis. To model a dynamic yield curve, we identify four broad pattern changes in the yield curve based on shifts in the long rate relative to changes in the short rate: no change, rotation, shift and pivot patterns. As implied, a no change pattern in the yield curve results when both the short and long rate demonstrate no relative shift from previous values.

A rotation pattern occurs when one end of the yield curve changes while the opposite end remains fixed, e.g., a rotation pattern results from a tightening (easing) in Fed policy, thereby increasing (decreasing) the short rate, but with no concurrent change in the long rate. Given the equality of Equation 4, if the long rate remains constant and the short rate increases (decreases), then the expected long spot rate must decrease (increase). Based on Expectation Theory, a lower expected spot rate results in a lower (higher) discount rate implying increased (decreased) subsequent six month equity returns. A rotation pattern may also occur if the short rate remains fixed and long rates change. This pattern results when the Fed and investors have incongruous views of future economic activity and inflation. A decrease (increase) in the current long spot rate with the short 
spot rate fixed, implies a decrease (increase) in the future spot rate and corresponding discount rate. Note that research using only Fed policy as a proxy for economic activity and as an explanatory variable does not identify this significant economic shift in investor expectations.

A shift pattern in the yield curve occurs when all rates change in the same direction with similar relative incremental conversion. An increase (decrease) in the short rate is accompanied by an increase (decrease) in the long rate implying that investors' expectations of future economic activity and anticipated inflation is congruous with monetary authorities' expectations.

A pivot pattern occurs when short and long rates inversely change around a fixed medium rate. For example, a Fed's tight monetary policy will lead to an increase in the short rate while the long rate drops. Investors may expect forward rates to drop due to decreased economic activity or an increase in the Fed's resolve to fight inflation. In contrast, a decrease in the short rate accompanied by an increase in the long rate implies investors' expectation of increased future economic activity or increased future inflation expectations.

\section{DATA}

Excess stock market returns are computed as the excess returns of a market index over the riskfree asset return, which is common in the relevant literature. Specifically we calculate the continuously compounded log return of the FTSE All Share index minus the short-term bank rate, with data on the stock prices derived from the Global Financial Database. The short-term interest rate is obtained from the Three Centuries of Data (Version 2.3) maintained by the Bank of England at: http://www.bankofengland.co.uk/research/Pages/datasets/default.aspx. This data is available till April, 2016. The data is then updated till end of our sample period from International Financial Statistics of the International Monetary Fund. We compute the volatility of excess stock market returns using the squared values of the equity premium. The term-spread is the difference between the long-term yield on consols less the short-term interest rate, with the long-term rate again derived from the Three Centuries of Data and International Financial Statistics. For US and South Africa stock prices measured by the S\&P500 and the Johannesburg All Share Index are obtained from the Global Financial Database. For South Africa, short- and long-term interest rates are also derived from the same source, with 10 year government bond yields serving as the measure of the long-term rate and the 3-month Treasury bill rate being the short-term rate. For the US the data on the long-term interest rate (10 year government bond yield) is obtained from the data segment of Professor Robert J. Shiller's website: http://www.econ.yale.edu/ shiller/data.htm, and the short-term rate comes from the website of Professor Amit Goyal: http://www.hec.unil.ch/agoyal/. The short-term interest rate is measured in terms of the three- 
month Treasury bill rate from 1920 onwards, and prior is based on an estimation, as in Welch and Goyal (2008), using the Commercial paper rates for New York City, which are obtained from the National Bureau of Economic Research (NBER) Macrohistory database. Professor Goyal's data ends in 2016:12, and hence, data for the next two months are obtained from the FRED database of the Federal Reserve Bank of St. Louis. The data sample covers the monthly periods of 1753:08 to 2017:02, 1871:02-2017:02 and 1936:01-2017:02 for UK, US and South Africa (SA), with the start and end dates being purely driven by the availability of data of the three variables involved.

As noted earlier in this research, changes in the yield curve pattern can result from either increases or decreases in the short term and/or long term rates and contain economic and expectations information not present in studies employing static yield spreads or fixed long rate assumptions. We identify a change in either the long-term or the short-term rate if the rate is more than one fifth of one standard deviation difference from the previous rate. Because interest rates have had a significant long-term variance over our 264-year sample period, we use a rolling ten-year period to determine the standard deviation. Using changes in the short and long rates, we classify the yield pattern into nine categories: no change, pivot clockwise, pivot counterclockwise, rotate long rate down, rotate long rate up, rotate short rate down, rotate short rate up, shift up and shift down. The specific pattern changes are categorized as follows:

- No change (Nochg): both short and long term rates stay the same

- Pivot clockwise (Pivclo): short term rates increase and long term rates decrease

- Pivot counterclockwise (Pivcnt): short term rates decrease and long term rates increase

- Rotate long down (Roldo): Short term stay the same, long term rates decrease

- Rotate long up (Rolup): Short term stay the same, long term rates increase

- Rotate short down (Rosdo): Short term rates decrease, long term stay the same

- Rotate short up (Rosup): Short term rates increase, long term stay the same

- Shift up (Shiftup): Both short and long term rates increase

- Shift down (Shiftdo): both short and long term rates decrease

While no change, shift up, and shift down all imply no change in the term spread, the different patterns have different implications relative to economic conditions. Similarly, pivot clockwise, rotate short up, and rotate long down all decrease positive spreads but signal different expectations of future economic activity in a narrower term spread environment. Lastly, pivot counterclockwise, rotate short down, and rotate long up all increase the term spread but have different information sets relative to future economic activity. 
As can be seen from the summary statistics, reported in Table A1 in the Appendix of the paper, the equity premium of UK is skewed to the right, with excess kurtosis, resulting in a non-normal distribution. Excess returns for US and South Africa are skewed to the left, and with excess kurtosis, normality is again rejected. As can also be observed from Table A1, the squared equity premium, i.e., volatility, of all the three countries are skewed to the right and with excess kurtosis have non-normal distributions. These results provide a preliminary motivation to use the causalityin-quantiles test (to be discussed in the next section), given the heavy-tails.

\section{Methodology: NonParametric Quantile Causality Test}

In this section, we briefly the present the methodology for the detection of nonlinear causality via a hybrid approach developed by Balcilar et al. (2016), which in turn is based on the frameworks of Nishiyama et al. (2011) and Jeong et al. (2012).

Let $y_{t}$ denote excess stock returns and $x_{t}$ denote the predictor variable, in our case the term-spread, its patterns and the interaction between the term-spread with the various patterns (as described in the data segment above) considered one at a time. Formally, suppose $Y_{t-1} \equiv\left(y_{t-1}, \ldots, y_{t-p}\right)$, $X_{t-1} \equiv\left(x_{t-1}, \ldots, x_{t-p}\right), Z_{t}=\left(X_{t}, Y_{t}\right)$ and $F_{y_{t} \mid Z_{t-1}}\left(y_{t}, Z_{t-1}\right)$ and $F_{y_{t} \mid Y_{t-1}}\left(y_{t}, Y_{t-1}\right)$ denote the conditional distribution functions of $y_{t}$ given $Z_{t-1}$ and $Y_{t-1}$, respectively. If we denote $Q_{\theta}\left(Z_{t-1}\right) \equiv Q_{\theta}\left(y_{t} \mid Z_{t-1}\right)$ and $Q_{\theta}\left(Y_{t-1}\right) \equiv Q_{\theta}\left(y_{t} \mid Y_{t-1}\right)$, we have $F_{y_{t} \mid Z_{t-1}}\left\{Q_{\theta}\left(Z_{t-1}\right) \mid Z_{t-1}\right\}=\theta$ with probability one. Consequently, the (non)causality in the $\boldsymbol{\theta}$-th quantile hypotheses to be tested are:

$$
\begin{aligned}
& H_{0}: P\left\{F_{y_{t} \mid Z_{t-1}}\left\{Q_{\theta}\left(Y_{t-1}\right) \mid Z_{t-1}\right\}=\theta\right\}=1, \\
& H_{1}: P\left\{F_{y_{t} \mid Z_{t-1}}\left\{Q_{\theta}\left(Y_{t-1}\right) \mid Z_{t-1}\right\}=\theta\right\}<1 .
\end{aligned}
$$

Jeong et al. (2012) employ the distance measure $J=\left\{\varepsilon_{t} E\left(\varepsilon_{t} \mid Z_{t-1}\right) f_{z}\left(Z_{t-1}\right)\right\}$, where $\varepsilon_{t}$ is the regression error term and $f_{z}\left(Z_{t-1}\right)$ is the marginal density function of $Z_{t-1}$. The regression error $\varepsilon_{t}$ emerges based on the null hypothesis in (1), which can only be true if and only if $E\left[1\left\{y_{t} \leq Q_{\theta}\left(Y_{t-1}\right) \mid Z_{t-1}\right\}\right]=\theta$ or, equivalently, $1\left\{y_{t} \leq Q_{\theta}\left(Y_{t-1}\right)\right\}=\theta+\varepsilon_{t}$, where $\mathbf{1}\{\cdot\}$ is an indicator function. Jeong et al. (2012) show that the feasible kernel-based sample analogue of $J$ has the following form:

$$
\hat{J}_{T}=\frac{1}{T(T-1) h^{2 p}} \sum_{t=p+1}^{T} \sum_{s=p+1, s \neq t}^{T} K\left(\frac{Z_{t-1}-Z_{s-1}}{h}\right) \hat{\varepsilon}_{t} \hat{\varepsilon}_{s} .
$$


where $K(\cdot)$ is the kernel function with bandwidth $h, T$ is the sample size, $p$ is the lag order, and $\hat{\varepsilon}_{t}$ is the estimate of the unknown regression error, which is estimated as follows:

$$
\hat{\varepsilon}_{t}=1\left\{y_{t} \leq Q_{\theta}\left(Y_{t-1}\right)\right\}-\theta
$$

$\hat{Q}_{\theta}\left(Y_{t-1}\right)$ is an estimate of the $\theta^{\text {th }}$ conditional quantile of $y_{t}$ given $Y_{t-1}$, and we estimate $\hat{Q}_{\theta}\left(Y_{t-1}\right)$ using the nonparametric kernel method as

$$
\hat{Q}_{\theta}\left(Y_{t-1}\right)=\hat{F}_{y_{t} \mid Y_{t-1}}^{-1}\left(\theta \mid Y_{t-1}\right),
$$

where $\hat{F}_{y_{t} \mid Y_{t-1}}\left(y_{t} \mid Y_{t-1}\right)$ is the Nadarya-Watson kernel estimator given by

$$
\hat{F}_{y_{t} \mid Y_{t-1}}\left(y_{t} \mid Y_{t-1}\right)=\frac{\sum_{s=p+1, s t t}^{T} L\left(\left(Y_{t-1}-Y_{s-1}\right) / h\right) 1\left(y_{s} \leq y_{t}\right)}{\sum_{s=p+1, s \neq t}^{T} L\left(\left(Y_{t-1}-Y_{s-1}\right) / h\right)},
$$

with $L(\cdot)$ denoting the kernel function and $h$ the bandwidth.

As an extension to Jeong et al. (2012)'s framework, Balcilar et al., (2016) additionally develop a test for the second moment. In particular, we can now extend the framework testing for the causality running from the term-spread, its patterns and interactive effects to the volatility of excess returns. Adopting the approach in Nishiyama et al. (2011), higher order quantile causality can be specified as:

$$
\begin{array}{ll}
H_{0}: P\left\{F_{y_{t}^{k} \mid Z_{t-1}}\left\{Q_{\theta}\left(Y_{t-1}\right) \mid Z_{t-1}\right\}=\theta\right\}=1 & \text { for } k=1,2, \ldots, K \\
H_{1}: P\left\{F_{y_{t}^{k} \mid Z_{t-1}}\left\{Q_{\theta}\left(Y_{t-1}\right) \mid Z_{t-1}\right\}=\theta\right\}<1 & \text { for } k=1,2, \ldots, K
\end{array}
$$

Integrating the entire framework, we define that $x_{t}$ Granger causes $y_{t}$ in quantile $\theta$ up to the $k^{t h}$ moment using Eq. (11) to construct the test statistic of Eq. (10) for each $k$. The causality-in-variance test can be calculated by replacing $\boldsymbol{y}_{\boldsymbol{t}}$ in Eqs. (7) and (8) with $\boldsymbol{y}_{\boldsymbol{t}}^{2}$ - measuring the volatility of excess stock returns However, it can be shown that it is not easy to combine the different statistics for each $k=1,2, \ldots, K$ into one statistic for the joint null in Eq. (11), because the statistics are mutually correlated (Nishiyama et al., 2011). To efficiently address this issue, Balcilar et al. (2016), include a sequential-testing method as described in Nishiyama et al. (2011). First, as in Balcilar et al. (2016), we test for the nonparametric Granger causality in the first moment (i.e. $k=1)$. Nevertheless, failure to reject the null for $k=1$ does not automatically leads to no-causality in the second moment. Thus, we can still construct the tests for $k=2$, as discussed in detail in Balcilar et al. (2016). The empirical implementation of causality testing via quantiles entails specifying three important choices: the bandwidth $h$, the lag order $p$, and the kernel type for $K(\cdot)$ and $L(\cdot)$. In this study, 
a lag order (of one) is used on the basis of the Schwarz information criterion (SIC). Note that, with respect to choosing lags, the SIC is considered parsimonious compared with other lag-length selection criteria, since it helps to overcome the issue of the over-parameterization that typically arises with nonparametric frameworks. ${ }^{2}$ The bandwidth value is chosen by employing least squares cross-validation techniques. ${ }^{3}$ Finally, for $K(\cdot)$ and $L(\cdot)$, Gaussian-type kernels are employed.

\section{EMPIRICAL RESULTS}

Though our objective is to analyse the causality-in-quantiles running from the term-spread, its patterns, and the interaction, to equity premium and its volatility, for the sake of completeness and comparability, we also conduct the standard linear Granger causality test based on VARs. The results are reported in Table 1 . The null hypotheses that various predictors does not Grangercause excess stock returns are rejected at the 5\% significance level, in four (term-spread, Pivent, Roldo, and Rolup) out of the nineteen cases considered.

\section{[INSERT TABLE 1 HERE.]}

To further motivate the use of the nonparametric quantile-in-causality approach, we investigate whether the relationship between asset returns and the predictors is nonlinear or not. To assess the existence of nonlinearity, we apply the Brock et al. (1996) (hereforth, BDS) test on the residuals of the excess returns equation in the VAR model involving the various predictors considered one at a time. The z-statistics of the BDS test are reported in Table 2 and, the null hypothesis of no serial dependence across various dimensions is overwhelmingly rejected in all cases. These results provide strong evidence of nonlinearity in the relationship between stock returns and the various predictors considered individually. Consequently, the evidence of predictability for the excess stock returns emanating from the four predictors in the linear Granger causality tests cannot be relied upon.

[INSERT TABLE 2 HERE. ]

\footnotetext{
${ }^{2}$ Hurvich and Tsai (1989) examine the Akaike information criterion (AIC) and show that it is biased towards selecting an over-parameterized model, whereas the SIC is asymptotically consistent.

${ }^{3}$ For each quantile, we determine the bandwidth $h$ using the leave-one-out least-squares cross validation method of Racine and Li (2004) and Li and Racine (2004).
} 
Given this, we now turn our attention to the nonparametric causality-in-quantiles test, i.e. a framework that, by design, is robust to the above mentioned econometric problem of nonlinearity. Table 3 highlights the outcome for the excess return series (Panel A) and the volatility series (Panel B). We find evidence for a nonlinear reaction of the excess return series to the term spread at the 0.7 and 0.75 quantile. In line with the linear Granger causality test, we also find the rotation long down important at a comparable quantile level indicating a stronger influence of a long rate increase on the upper conditional distribution.

\section{[INSERT TABLE 3 HERE.]}

Nonlinear causality strengthens when focusing on the volatility series. We observe a significant impact of the term spread across almost all quantiles. Since the test statistics are normalized, the effect of the moderate-upper quantiles on the conditional distribution of volatility is stronger than the one for the lower quantiles. We also observe significant influences for the pattern changes and interaction terms concentrated above the median (with the highest quantile being an exception). The strongest evidence for nonlinearity is reported for rotation long up. We only find weak evidence for reactions below the median. Applying the linear granger causality test would, in turn, lead to misleading results, because the impact of the pattern changes mainly affect the upper conditional distribution of stock market volatility.

\subsection{Robustness and Comparative Analyses}

In this segment, we conduct additional tests to analyze the robustness of our results, and also compare our findings with that of the US and SA. First, we observe that, our findings are only slightly affected when we increase the threshold for constructing the pattern changes to, say, 0.2 of the standard deviation's difference from the previous rate (see Table 4). However, with respect to the excess return series, rotation long down becomes insignificant implying that we do not observe any influence from pattern changes at all.

Given the long-span of data for the UK, it should not be surprising that there could be structural breaks in the relationship between excess returns and the term-spread. In this regard, we conducted the Bai and Perron (2003) tests of 1 to $M$ globally determined multiple breaks and detected a regime change at 1825:02 for both the conditional mean of excess returns and in its relationship with the term spread, based on the powerful UDmax and WDmax tests (allowing for a maximum of five breaks, with 15 percent trimming, and error distributions to differ across the breaks). We 
repeat the causality-in-quantiles analysis of the full-sample for the two sub-samples of: 1753:081825:01; 1825:02-2017:02. ${ }^{4}$ The results are conducted in Tables 5 and $6 .^{5}$

[INSERT TABLES 4, 5, and 6 HERE.]

In line with the full sample, we find relatively poor support of nonlinear effects of the predictors in the first sub-sample for excess returns (Table 5a). The asymmetric effects of pattern changes on volatility mainly reduces to the 0.6 and 0.65 quantile (Table 5b). The interactive effect of the rotation long down pattern change is found to be completely insignificant. In the second subsample, influences on the volatility series increases to the 0.7 and 0.8 quantile (Table $6 \mathrm{~b}$ ). The no change, rotation long down and rotation long up pattern expand their range of significance close to the median (0.55). In contrast to previous research that assumed the long rate is static with a focus on the short rate, these results indicate that the long rate has a greater impact on returns within the median volatility range.

Compared to the first subsample, relatively strong nonlinear effects are observed in terms of the excess return series (Table 6a). Although there is only weak evidence for a significant impact around the median (0.35-0.55 quantile), almost all pattern changes and interaction terms become significant at the remaining quantiles. On balance, the effects are stronger above than below the median with the rotation long up and the related interaction term being the most important pattern change.

\footnotetext{
${ }^{4}$ Shifts in volatility of interest rates may be due to the Panic of 1825 and subsequent monetary policies of the United Kingdom. The Panic of 1825 is considered the first modern economic crisis not attributable to an external event. Prior to 1825, the British government suspended the Gold standard and engaged in a period of expansionary monetary policy to support the Napoleonic wars. The easy access to money led to speculative investments in Latin America, including the imaginary country Poyais. To address inflationary pressure and restrict speculative investing, the British government re-established the Gold standard thereby constricting the money supply leading to the Panic of 1825.
}

\footnotetext{
${ }^{5}$ We also repeated the linear Granger causality test for the two sub-samples, and obtained similar (weak) results to those reported for the full sample in Table 1. In fact, the term spread was found to be insignificant in the first subsample. Complete details of these results are available upon request from the authors.
} 
As a final robustness check, we compare our findings with the US and South African (SA) data. Tables 7 and 8 present the results.

\section{[INSERT TABLES 7 AND 8 HERE.]}

With respect to the term spread, both countries experience significant nonlinear causality across almost all quantiles. Similar to the UK stock market, the impact of the pattern changes and interaction terms turns out to be largely insignificant for US excess returns (Table 7a) - a result in contradiction with that of Volkman et al., (2014), which may be do to the different linear model used by these authors. We actually, only find weak evidence for nonlinear causality around the median. Pivot clockwise, pivot counter clockwise, rotation up, and shift up remain insignificant. We, however, do not observe significant influences of pattern changes in terms of the volatility series (Table 7b), though the term spread does play an important role. In case of South Africa, a strong influence of pattern changes on the excess return series is reported for the median and up to the 0.85 quantile (Table 8 a). In addition, a significant reaction to the role up pattern change and its interactive effect is detected for a bearish market scenario. Finally, with respect to the volatility series in Table $8 \mathrm{~b}$, the term-spread, no change and its interactive effect become significant mainly barring the lower and upper quantiles.

In general, our results tend to suggest the importance of the term spread in predicting both returns and volatility of both developed and emerging markets. However for the UK, pattern changes and the interaction of pattern changes with the term-spread tends to also play an important role in predicting especially volatility at the upper end of its conditional distribution. In addition, the effect on excess returns from pattern changes and the interaction is found to have improved markedly more recently, as suggested by a sub-sample analysis, which in turn, is also found to hold true in the emerging market of South Africa. Interestingly, for the US excess returns and its volatility is primarily driven by the term spread on its own, rather than pattern changes, and the interaction terms.

\section{CONCLUSION}

This paper assesses, for the first time, the predictive ability of the term-spread, its pattern changes, and the interaction of pattern changes with the term-spread for excess stock returns in the UK, as well as its volatility, over the monthly period 1753:08-2017:02, using a nonparametric causality-inquantiles test developed by Balcilar et al. (2016). In addition, we also compare the results with 
historical data for a developed country, i.e., the US over 1871:02 to 2017:02, and an emerging economy namely, South Africa, over 1936:01-2017:02.

Starting off with a linear framework as generally done in the literature, we observe that, while term spread on its own plays an important role in predicting the excess returns of the UK, pattern changes and the interaction of pattern changes with the term-spread are not of major importance. However, formal tests of nonlinearity confirm that the linear model is misspecified and results obtained from it cannot be relied upon. Using the nonparametric causality-in-quantiles test, which is robust to such misspecification, we obtain similar results at that of the linear model for excess returns, but are able to show the importance of term spread, pattern changes, and the interaction of pattern changes with the term-spread in predicting the volatility of the equity premium, especially at the upper end of its conditional distribution, i.e., when volatility is relatively high. But, we also observe that over time, term spread, pattern changes, and the interaction of pattern changes with the term-spread have also become important in predicting the excess returns of the UK, barring when the market is performing at its normal mode, i.e., when we consider the median of the conditional distribution, which could be an indication of herding by investors when the market is not in its bearish and bullish phases. Clearly then for the UK, besides the term spread, pattern changes and the interaction of pattern changes with the term-spread, is found to have important predictive content for excess returns and, especially, (high) volatility. Finally, while the importance of the term spread in general is also found for the excess returns and volatility of the US and South Africa, the role of pattern changes and the interaction of pattern changes with the term-spread is only restricted to the excess returns of the latter.

As is well-known, predictability of stock returns and volatility (when interpreted as uncertainty) becomes key inputs to investment decisions and portfolio choices for practitioners in finance. Further, volatility is the most important variable in the pricing of derivative securities, and financial risk management according to the Basle Accord. Moreover, financial market volatility can have wide repercussions on the economy as a whole, via its effect on real economic activity and public confidence. At the same time, academics in finance are interested in predictability of stock market movements, since they have important implications for tests of market efficiency, which in turn, helps to produce more realistic asset pricing models. Given that, predicting stock markets is important for practitioners, academics and policymakers alike, our findings are of paramount importance to all these groups of economic agents. The fact that term spread, as well as pattern changes and the interaction of pattern changes with the term-spread, can predict both first and second moments of the equity premium, not only suggests the violation of the efficient market hypothesis, but should also be of assistance in asset allocation and policy-making that aims to curb 
financial market volatility. However, it must be emphasized that to obtain accurate predictability of equity return and volatility, economic agents would need to rely on nonlinear rather than linear econometric approaches. As part of future research, it would be interesting to extend our study to examine if these results hold in an out-of-sample exercise given that in-sample predictability does not guarantee the same in a forecasting set-up (Rapach and Zhou, 2013). 


\section{References}

Acosta-Gonzalez, E., and Fernandez-Rodriguez, F. (2007). Model selection via genetic algorithms illustrated with cross-country growth data. Empirical Economics, 33, 313-337.

Ang, A., Piazzesi, M., and Wei, M. (2006). What does the yield curve tell us about GDP growth? Journal of Econometrics, 131, 359-403.

Bai, J., and Perron, P. (2003). Computation and analysis of multiple structural change models. Journal of Applied Econometrics, 18, 1-22.

Bai, Z., Li, H., Wong, W-K., and Zhang, B. (2011). Multivariate causality tests with simulation and application. Statistics \& Probability Letters, 81(8), 1063-1071.

Bai, Z., Wong, WK., and Zhang, B. (2010). Multivariate linear and nonlinear causality tests. Mathematics and Computers in Simulation, 81(1), 5-17.

Balcilar, M., Bekiros, S., and Gupta, R. (2016). The role of news-based uncertainty indices in predicting oil markets: a hybrid nonparametric quantile causality method. Empirical Economics, doi:10.1007/s00181-016-1150-0.

Bekiros, S., Gupta, R., and Majumdar, A. (2016). Incorporating Economic Policy Uncertainty in US Equity Premium Models: A Nonlinear Predictability Analysis. Finance Research Letters, 18(1), 291-296.

Boudoukh, J., Matthew, R., Whitelaw, R. (1997). Nonlinearities in the relation between the equity risk premium and the term structure. Management Science, 43, 371-385.

Boudoukh, J., Richardson, M., and Smith, T. (1993). Is the ex ante risk premium positive? A new approach to testing conditional asset pricing models. Journal of Financial Economics, 34, 387-408.

Brock, W., Dechert, D., Scheinkman, J., and LeBaron, B. (1996). A test for independence based on the correlation dimension. Econometric Reviews, 15, 197-235.

Campbell, J. Y. (1987). Stock Returns and Term Structure. Journal of Financial Economics, 18(2), 373399.

Chen, N.-F., R. Roll, and S. A. Ross. (1986). Economic forces and the stock market. Journal of Business, 59, 383-403.

Diebold, F. X., Rudebusch, G. D., and Aruoba, S. B. (2006). The macroeconomy and the yield curve: A dynamic latent factor approach. The Journal of Econometrics, 131, 309-338.

Diks, C. G. H. and Panchenko, V. (2005). A note on the Hiemstra-Jones test for Granger noncausality. Studies in Nonlinear Dynamics and Econometrics, 9(2), 1-7. 
Diks, C. G. H. and Panchenko, V. (2006). A new statistic and practical guidelines for nonparametric Granger causality testing. Journal of Economic Dynamics and Control, 30(9-10), 16471669.

Estrella, A and Mishkin, F. (1996). The yield curve as a predictor of US recessions. Federal Reserve Bank of New York. Current Issues in Economics and, Finance, 2(7), 1-6.

Estrella, A., and Mishkin, F. (1998). Predicting US recessions: Financial variables as leading indicators. Review of Economics and Statistics, 80, 45-61.

Fama, E., and French, K. (1989). Business conditions and expected returns on stocks and bonds. Journal of Financial Economics, 25, 23-49.

Fernandez-Perez, Adrian, Fernandez-Rodriguez, Fernando and Sosvilla-Rivero, Simon. (2014). The term structure of interest rates as predictor of stock returns: Evidence for the IBEX 35 during a bear market. International Review of Economics and Finance, 31, 21-33.

Ferreira, E.. Martinez Serna, M. I., Navarro, E., and Gonzalo Rubio, I. (2008). Economic sentiment and yield spreads in Europe. European Financial Management, 14, 206-221.

Harvey, C. (1997). The relation between the term structure of interest rates and Canadian economic growth. Canadian Journal of Economics, 30, 169-193.

Hiemstra, C. and Jones, J.D. (1994). Testing for linear and nonlinear Granger causality in the stock price-volume relation. Journal of Finance, 49(5), 1639-1664.

Hurvich, C., M., and Tsai, C. (1989). Regression and time series model selection in small samples. Biometrika, 76(2), 297-307.

Jeong, K., Härdle, W.K., and Song, S. (2012). A consistent nonparametric test for causality in quantile. Econometric Theory, 28(4), 861-887.

Li, Q., and Racine, J.S. (2004). Cross-validated local linear nonparametric regression. Statistica Sinica, 14, 485-512.

McCown, J. R. (1999). The effects of inverted yield curves on asset returns. Financial Review, 34,10926.

McCown, J. R. (2001). Yield curves and international equity returns. Journal of Banking and Finance, $25,767-788$.

Moench, E. (2012). Term structure surprises: The predictive content of curvature, level, and slope. Journal of Applied Econometrics, 27, 574-602,

Nishiyama, Y., Hitomi, K., Kawasaki, Y., and Jeong, K. (2011). A consistent nonparametric test for nonlinear causality - Specification in time series regression. Journal of Econometrics, 165, 112127. 
Nyberg, H. (2013). Predicting bear and bull stock markets with dynamic binary times series models. Journal of Banking and Finance, 37, 3351-3363.

Ostdiek, B. (1998). The world ex ante risk premium: An empirical investigation. Journal of International Money and Finance, 17. 967-999.

Racine, J.S., and Li, Q. (2004). Nonparametric estimation of regression functions with both categorical and continuous data. Journal of Econometrics, 119, 99-130.

Rapach, D., and Zhou, G. (2013). Forecasting stock returns. In: Elliott, G., Timmermann, A., Eds. Handbook of Economic Forecasting, 328-383, Amsterdam: Elsevier.

Resnick, B. G., and Shoesmith, G. L. (2002). Using the yield curve to time the stock market. Financial Analysts Journal, 58, 82-90.

Siegel, J. J. (1998). Stocks for the long run (2nd ed.). New York: McGraw-Hill.

Volkman, D. A., Maisondieu Laforge, O. J. P. and Wohar, M. (2012). Interactive Effect of Changes in the Shape of the Yield Curve and Conditional term spread on expected equity returns. Applied Financial Economics, 22, 1491-1500.

Volkman, D. A., Maisondieu Laforge, O. J. P. and Wohar, M. (2014). The conditional influence of term spread and pattern changes on future equity returns. Applied Economics, 46(9), 913-923.

Welch, I., and Goyal, A. (2008). A Comprehensive Look at The Empirical Performance of Equity Premium Prediction. The Review of Financial Studies, 21(4):1455-1508.

Wheelock, D. C., Wohar, M. E. (2009). Can the term spread predict output growth and recessions? A survey of the literature. Review. Federal Reserve Bank of St. Lonis, 91, 419-440. 
Table 1. Linear Granger Causality Test

\begin{tabular}{|l|l|l|}
\hline Variable & $F$-stat & $p$-value \\
\hline TermSpread & 16.6353 & $0.0000^{*}$ \\
\hline Nochg & 0.28523 & 0.5933 \\
\hline Pivclo & 0.51162 & 0.4745 \\
\hline Pivent & 5.15929 & $0.0232^{*}$ \\
\hline Rosdo & 2.55022 & 0.1104 \\
\hline Rosup & 1.78606 & 0.1815 \\
\hline Roldo & 12.0636 & $0.0005^{*}$ \\
\hline Rolup & 10.7482 & $0.0011^{*}$ \\
\hline Shiftup & 0.27799 & 0.5981 \\
\hline Shiftdo & 3.44376 & 0.0636 \\
\hline TS.Nochg & 0.00108 & 0.9737 \\
\hline TS.Pivclo & 0.17271 & 0.6778 \\
\hline TS.Pivent & 0.07028 & 0.7910 \\
\hline TS.Rosdo & 1.44389 & 0.2296 \\
\hline TS.Rosup & 2.95087 & 0.0860 \\
\hline TS.Roldo & 0.55243 & 0.4574 \\
\hline TS.Rolup & 0.13272 & 0.7157 \\
\hline TS.Shiftup & 0.14307 & 0.7053 \\
\hline TS.Shiftdo & 0.09766 & 0.7547 \\
\hline
\end{tabular}

Note: * indicates rejection of null hypothesis of no Granger causality at 5 percent level of significance. 
Table 2. BDS Test of Nonlinearity

\begin{tabular}{|l|l|l|l|l|l|}
\hline \multirow{2}{*}{ Variable } & \multicolumn{5}{|c|}{ Dimension } \\
\cline { 2 - 6 } & 2 & 3 & 4 & 5 & 6 \\
\hline Term Spread & $17.1055^{* * *}$ & $22.4139^{* * *}$ & $26.3372^{* * *}$ & $30.1824^{* * *}$ & $33.9381^{* * *}$ \\
\hline Nochg & $16.7646^{* * *}$ & $22.1965^{* * *}$ & $26.2175^{* * *}$ & $30.1320^{* * *}$ & $33.9555^{* * *}$ \\
\hline Pivclo & $16.8071^{* * *}$ & $22.2237^{* * *}$ & $26.2390^{* * *}$ & $30.1663^{* * *}$ & $34.0180^{* * *}$ \\
\hline Pivent & $16.9165^{* * *}$ & $22.3955^{* * *}$ & $26.5060^{* * *}$ & $30.4490^{* * *}$ & $34.3188^{* * *}$ \\
\hline Rosdo & $16.6956^{* * *}$ & $22.1035^{* * *}$ & $26.1336^{* * *}$ & $30.0392^{* * *}$ & $33.8530^{* * *}$ \\
\hline Rosup & $16.9032^{* * *}$ & $22.3437^{* * *}$ & $26.3718^{* * *}$ & $30.2965^{* * *}$ & $34.1120^{* * *}$ \\
\hline Roldo & $16.8455^{* * *}$ & $22.3952^{* * *}$ & $26.4702^{* * *}$ & $30.4252^{* * *}$ & $34.2734^{* * *}$ \\
\hline Rolup & $16.8068^{* * *}$ & $22.0782^{* * *}$ & $26.1054^{* * *}$ & $30.0418^{* * *}$ & $33.9282^{* * *}$ \\
\hline Shiftup & $16.8060^{* * *}$ & $22.2140^{* * *}$ & $26.2240^{* * *}$ & $30.1420^{* * *}$ & $33.9810^{* * *}$ \\
\hline Shiftdo & $16.8952^{* * *}$ & $22.3141^{* * *}$ & $26.3583^{* * *}$ & $30.2822^{* * *}$ & $34.1098^{* * *}$ \\
\hline TS.Nochg & $13.2825^{* * *}$ & $16.4354^{* * *}$ & $19.1268^{* * *}$ & $21.1705^{* * *}$ & $23.1151^{* * *}$ \\
\hline TS.Pivclo & $13.2751^{* * *}$ & $16.4146^{* * *}$ & $19.0971^{* * *}$ & $21.1348^{* * *}$ & $23.0711^{* * *}$ \\
\hline TS.Pivent & $13.2916^{* * *}$ & $16.4517^{* * *}$ & $19.1373^{* * *}$ & $21.1820^{* * *}$ & $23.1270^{* * *}$ \\
\hline TS.Rosdo & $13.2364^{* * *}$ & $16.3314^{* * *}$ & $18.9860^{* * *}$ & $21.0120^{* * *}$ & $22.9466^{* * *}$ \\
\hline TS.Rosup & $13.0979^{* * *}$ & $16.2984^{* * *}$ & $19.0235^{* * *}$ & $21.1047^{* * *}$ & $23.0399^{* * *}$ \\
\hline TS.Roldo & $13.2108^{* * *}$ & $16.3447^{* * *}$ & $19.0501^{* * *}$ & $21.0893^{* * *}$ & $23.0119^{* * *}$ \\
\hline TS.Rolup & $13.2689^{* * *}$ & $16.4181^{* * *}$ & $19.1038^{* * *}$ & $21.1457^{* * *}$ & $23.0904^{* * *}$ \\
\hline TS.Shiftup & $13.2551^{* * *}$ & $16.4050^{* * *}$ & $19.0892^{* * *}$ & $21.1245^{* * *}$ & $23.0591^{* * *}$ \\
\hline TS.Shiftdo & $13.2712^{* * *}$ & $16.4198^{* * *}$ & $19.1105^{* * *}$ & $21.1512^{* * *}$ & $23.0976^{* * *}$ \\
\hline
\end{tabular}

Note: Entries correspond to the $z$-statistic of the BDS test; *** indicates rejection of null hypothesis of iid of the residuals obtained from the excess returns equation of the VAR model involving the equity premium and the predictor at 1 percent level of significance. 
Table 3a: Quantile Causality Results for UK Excess Returns

\begin{tabular}{|c|c|c|c|c|c|c|c|c|c|c|c|c|c|c|c|c|c|}
\hline & \begin{tabular}{|l|}
0.10 \\
\end{tabular} & 0.15 & 0.20 & 0.25 & 0.30 & 0.35 & 0.40 & 0.45 & 0.50 & 0.55 & 0.60 & 0.65 & 0.70 & 0.75 & 0.80 & 0.85 & 0.90 \\
\hline TS & 0.81 & 0.88 & 0.84 & 0.87 & 0.82 & 0.99 & 1.06 & 1.25 & 1.54 & 1.54 & 1.60 & 1.93 & $2.18^{*}$ & $2.14^{*}$ & 1.94 & 1.75 & 0.98 \\
\hline Nochg & 0.42 & 0.53 & 0.48 & 0.32 & 0.25 & 0.08 & 0.04 & 0.01 & 0.04 & 0.09 & 0.12 & 0.23 & 0.34 & 0.53 & 0.50 & 0.61 & 0.35 \\
\hline Pivclo & 0.34 & 0.42 & 0.30 & 0.22 & 0.13 & 0.06 & 0.03 & 0.01 & 0.01 & 0.07 & 0.16 & 0.27 & 0.42 & 0.55 & 0.49 & 0.67 & 0.41 \\
\hline Pivent & 0.49 & 0.57 & 0.63 & 0.64 & 0.30 & 0.22 & 0.07 & 0.04 & 0.03 & 0.10 & 0.18 & 0.22 & 0.30 & 0.37 & 0.39 & 0.50 & 0.29 \\
\hline Rosdo & 0.39 & 0.46 & 0.40 & 0.33 & 0.33 & 0.18 & 0.12 & 0.04 & 0.02 & 0.07 & 0.13 & 0.31 & 0.38 & 0.46 & 0.46 & 0.62 & 0.35 \\
\hline Rosup & \begin{tabular}{|l|}
0.42 \\
\end{tabular} & 0.45 & 0.39 & 0.30 & 0.20 & 0.17 & 0.19 & 0.20 & 0.12 & 0.15 & 0.23 & 0.32 & 0.43 & 0.45 & \begin{tabular}{|l|}
0.42 \\
\end{tabular} & 0.51 & 0.28 \\
\hline Roldo & \begin{tabular}{|l|}
0.43 \\
\end{tabular} & 0.55 & 0.58 & 0.46 & 0.53 & 0.49 & 0.63 & 0.91 & 1.31 & 1.75 & 1.84 & $2.00^{*}$ & $2.22 *$ & 1.56 & 1.21 & 1.41 & 0.55 \\
\hline Rolup & \begin{tabular}{|l|}
0.74 \\
\end{tabular} & 1.08 & 0.94 & 0.80 & 0.69 & 0.73 & 0.72 & 0.69 & 0.46 & 0.39 & 0.38 & 0.40 & 0.45 & 0.51 & 0.47 & 0.58 & 0.32 \\
\hline Shiftup & \begin{tabular}{|l|}
0.45 \\
\end{tabular} & 0.60 & 0.57 & 0.40 & 0.40 & 0.32 & 0.37 & 0.36 & 0.50 & 0.46 & 0.46 & 0.35 & 0.35 & 0.43 & 0.42 & 0.57 & 0.35 \\
\hline Shiftdo & 0.38 & 0.44 & 0.35 & 0.27 & 0.17 & 0.18 & 0.17 & 0.24 & 0.27 & 0.42 & 0.59 & 0.58 & 0.72 & 0.59 & 0.67 & 0.66 & 0.44 \\
\hline TS.Nochg & 0.61 & 0.76 & 0.66 & 0.48 & 0.33 & 0.20 & 0.18 & 0.15 & 0.18 & 0.23 & 0.27 & 0.46 & 0.57 & 0.90 & 0.82 & 0.73 & 0.38 \\
\hline TS.Pivclo & \begin{tabular}{|l|}
0.37 \\
\end{tabular} & 0.43 & 0.31 & 0.22 & 0.13 & 0.07 & 0.04 & 0.03 & 0.04 & 0.10 & 0.19 & 0.32 & 0.46 & 0.59 & 0.52 & 0.69 & 0.39 \\
\hline TS.Pivent & \begin{tabular}{|l|}
0.49 \\
\end{tabular} & 0.54 & 0.54 & 0.43 & 0.25 & 0.14 & 0.06 & 0.03 & 0.03 & 0.07 & 0.09 & 0.17 & 0.28 & 0.40 & 0.43 & 0.54 & 0.33 \\
\hline TS.Rosdo & \begin{tabular}{|l|}
0.37 \\
\end{tabular} & 0.42 & 0.32 & 0.24 & 0.18 & 0.14 & 0.12 & 0.10 & 0.10 & 0.15 & 0.24 & 0.39 & 0.55 & 0.62 & \begin{tabular}{|l|}
0.61 \\
\end{tabular} & 0.79 & 0.44 \\
\hline TS.Rosup & 0.55 & 0.60 & 0.53 & 0.38 & 0.24 & 0.13 & 0.09 & 0.10 & 0.05 & 0.05 & 0.08 & 0.16 & 0.24 & 0.33 & 0.38 & 0.52 & 0.32 \\
\hline TS.Roldo & 0.43 & 0.51 & 0.38 & 0.31 & 0.19 & 0.18 & 0.23 & 0.33 & 0.47 & 0.78 & 0.88 & 1.17 & 1.32 & 1.28 & 1.15 & 1.34 & 0.65 \\
\hline TS.Rolup & \begin{tabular}{|l|}
0.91 \\
\end{tabular} & 0.99 & 0.74 & 0.65 & 0.41 & 0.30 & 0.22 & 0.15 & 0.07 & 0.10 & 0.13 & 0.26 & 0.44 & 0.58 & 0.57 & 0.78 & 0.45 \\
\hline TS.Shiftup & 0.48 & 0.53 & 0.50 & 0.39 & 0.31 & 0.22 & 0.15 & 0.14 & 0.12 & 0.12 & 0.15 & 0.26 & 0.38 & 0.47 & 0.51 & 0.70 & 0.41 \\
\hline TS.Shiftdo & \begin{tabular}{|l|}
0.41 \\
\end{tabular} & 0.49 & 0.38 & 0.35 & 0.23 & 0.15 & 0.13 & 0.15 & 0.26 & 0.36 & 0.38 & 0.47 & 0.57 & 0.57 & \begin{tabular}{|l|}
0.58 \\
\end{tabular} & 0.65 & 0.45 \\
\hline
\end{tabular}

Note: Quantile causality results for the null hypothesis that term spread, pattern changes, and interaction terms do not Granger cause excess stock returns; * indicates rejection at the $5 \%$ significance level. 
Table 3b: Quantile Causality Results for UK Volatility

\begin{tabular}{|c|c|c|c|c|c|c|c|c|c|c|c|c|c|c|c|c|c|}
\hline & 0.10 & 0.15 & 0.20 & 0.25 & 0.30 & 0.35 & 0.40 & 0.45 & 0.50 & 0.55 & 0.60 & 0.65 & 0.70 & 0.75 & 0.80 & 0.85 & 0.90 \\
\hline TS & $2.12^{*}$ & $2.78^{*}$ & $3.22 *$ & $3.50 *$ & $3.74^{*}$ & $4.19 *$ & $4.38^{*}$ & $4.77^{*}$ & $4.87^{*}$ & $5.80^{*}$ & $5.75^{*}$ & $5.84^{*}$ & $5.74^{*}$ & $5.68^{*}$ & $5.15^{*}$ & $3.92 *$ & $2.89 *$ \\
\hline Nochg & 0.53 & 0.30 & 0.94 & 1.44 & 0.92 & 0.79 & 0.55 & 0.59 & 1.24 & $2.78^{*}$ & $2.78^{*}$ & $2.48^{*}$ & $3.61 *$ & $4.24 *$ & $3.66^{*}$ & 1.52 & 1.73 \\
\hline Pivclo & 0.49 & 0.34 & 1.29 & $2.13^{*}$ & 1.36 & 1.30 & 0.80 & 0.76 & 1.39 & $2.55^{*}$ & $2.56^{*}$ & $2.46^{*}$ & $3.12^{*}$ & $4.70^{*}$ & $4.04 *$ & 1.47 & 1.01 \\
\hline Pivent & 0.80 & 0.29 & 0.90 & 1.69 & 1.13 & 0.86 & 0.58 & 0.57 & 1.02 & $2.43^{*}$ & $2.63^{*}$ & $2.61 *$ & $3.13^{*}$ & $4.65^{*}$ & $4.13 *$ & 1.74 & 1.31 \\
\hline Rosdo & 0.42 & 0.56 & 1.24 & $1.98^{*}$ & 1.35 & 1.31 & 0.80 & 0.78 & 1.16 & $2.27 *$ & $2.28^{*}$ & $1.99 *$ & $2.59 *$ & $3.96^{*}$ & $3.35^{*}$ & 1.21 & 0.98 \\
\hline Rosup & 0.73 & 0.40 & 1.14 & 1.85 & 1.20 & 1.07 & 0.83 & 0.83 & 1.32 & $2.32 *$ & $2.55^{*}$ & $2.50 *$ & $2.89 *$ & $4.09 *$ & $3.40 *$ & 1.08 & 1.01 \\
\hline Roldo & 0.36 & 0.20 & 1.51 & $2.00^{*}$ & 1.55 & 1.52 & 1.00 & 0.97 & 1.79 & $2.72 *$ & $2.75^{*}$ & $2.28 *$ & $2.93 *$ & $4.70^{*}$ & $3.41 *$ & 1.15 & 1.00 \\
\hline Rolup & 0.35 & 0.38 & 1.35 & $2.22^{*}$ & 1.59 & 1.56 & 0.96 & 1.14 & 1.74 & $2.78^{*}$ & $2.91 *$ & $2.84^{*}$ & $3.28^{*}$ & $5.07 *$ & $4.50^{*}$ & 1.69 & 1.34 \\
\hline Shiftup & 0.33 & 0.27 & 1.27 & $2.34 *$ & 1.62 & 1.33 & 1.05 & 0.99 & 1.39 & $2.33^{*}$ & $2.41 *$ & $2.62^{*}$ & $3.19 *$ & $4.58^{*}$ & $4.04 *$ & 1.60 & 1.29 \\
\hline Shiftdo & 0.34 & 0.20 & 0.91 & 1.58 & 0.91 & 0.80 & 0.54 & 0.51 & 1.01 & $2.13^{*}$ & $2.10^{*}$ & 1.88 & $2.24 *$ & $3.68 *$ & $3.45^{*}$ & 1.26 & 1.04 \\
\hline TS.Nochg & 0.67 & 0.38 & 0.87 & 1.40 & 0.91 & 0.78 & 0.67 & 0.77 & 1.41 & $3.03^{*}$ & $3.30 *$ & $2.90 *$ & $4.24 *$ & $4.60 *$ & $4.00 *$ & 1.79 & $2.05^{*}$ \\
\hline TS.Pivclo & 0.50 & 0.34 & 1.29 & $2.12^{*}$ & 1.36 & 1.29 & 0.80 & 0.77 & 1.43 & $2.56^{*}$ & $2.58^{*}$ & $2.49 *$ & $3.15^{*}$ & $4.73 *$ & $4.06^{*}$ & 1.48 & 0.99 \\
\hline TS.Pivent & 0.76 & 0.27 & 0.87 & 1.68 & 1.13 & 0.84 & 0.58 & 0.58 & 1.01 & $2.44^{*}$ & $2.62 *$ & $2.62 *$ & $3.14^{*}$ & $4.67 *$ & $4.14^{*}$ & 1.75 & 1.32 \\
\hline TS.Rosdo & 0.41 & 0.52 & 1.19 & 1.94 & 1.31 & 1.30 & 0.78 & 0.68 & 1.00 & $2.17^{*}$ & $2.17^{*}$ & 1.83 & $2.48^{*}$ & $3.82^{*}$ & $3.19 *$ & 1.10 & 0.91 \\
\hline TS.Rosup & 0.73 & 0.41 & 1.13 & 1.80 & 1.17 & 1.03 & 0.82 & 0.78 & 1.28 & $2.21 *$ & $2.49 *$ & $2.47 *$ & $2.82 *$ & $3.96^{*}$ & $3.28 *$ & 0.99 & 0.95 \\
\hline TS.Roldo & 0.37 & 0.25 & 1.52 & $2.12^{*}$ & 1.63 & 1.59 & 1.02 & 0.98 & 1.82 & $2.81 *$ & $2.92 *$ & $2.36^{*}$ & $3.05^{*}$ & $4.85^{*}$ & $3.41 *$ & 1.15 & 1.01 \\
\hline TS.Rolup & 0.30 & 0.26 & 1.36 & $2.33^{*}$ & 1.64 & 1.62 & 1.05 & 1.16 & 1.85 & $2.99 *$ & $3.12 *$ & $3.06^{*}$ & $3.50 *$ & $5.31 *$ & $4.72^{*}$ & 1.81 & 1.42 \\
\hline TS.Shiftup & 0.34 & 0.30 & 1.34 & $2.39 *$ & 1.66 & 1.36 & 1.09 & 1.03 & 1.43 & $2.31 *$ & $2.41 *$ & $2.73^{*}$ & $3.28^{*}$ & $4.64^{*}$ & $4.08^{*}$ & 1.63 & 1.29 \\
\hline TS.Shiftdo & 0.33 & 0.21 & 0.88 & 1.56 & 0.85 & 0.73 & 0.51 & 0.48 & 0.99 & $2.10^{*}$ & 2.04* & 1.80 & $2.05^{*}$ & $3.55^{*}$ & $3.41 *$ & 1.26 & 1.03 \\
\hline
\end{tabular}

Note: Quantile causality results for the null hypothesis that term spread, pattern changes, and interaction terms do not Granger cause excess stock returns volatility; ${ }^{*}$ indicates rejection at the $5 \%$ significance level. 
Table 4a: Quantile Causality Results for UK Excess Returns (0.2 sd)

\begin{tabular}{|c|c|c|c|c|c|c|c|c|c|c|c|c|c|c|c|c|c|}
\hline & 0.10 & 0.15 & 0.20 & 0.25 & 0.30 & 0.35 & 0.40 & 0.45 & 0.50 & 0.55 & 0.60 & 0.65 & 0.70 & 0.75 & 0.80 & 0.85 & 0.90 \\
\hline TS & 0.81 & 0.88 & 0.84 & 0.87 & 0.82 & 0.99 & 1.06 & 1.25 & 1.54 & 1.54 & 1.60 & 1.93 & $2.18^{*}$ & 2.14* & 1.94 & 1.75 & 0.98 \\
\hline Nochg & 0.41 & 0.50 & 0.43 & 0.33 & 0.21 & 0.08 & 0.09 & 0.05 & \begin{tabular}{|l|}
0.19 \\
\end{tabular} & 0.36 & 0.36 & 0.41 & 0.44 & 0.63 & 0.56 & 0.67 & 0.34 \\
\hline Pivclo & 0.36 & \begin{tabular}{|l|}
0.43 \\
\end{tabular} & 0.33 & 0.23 & 0.14 & 0.06 & 0.04 & 0.01 & 0.01 & 0.07 & 0.14 & 0.26 & 0.37 & 0.49 & 0.47 & 0.63 & 0.40 \\
\hline Pivent & 0.44 & 0.57 & 0.58 & 0.51 & 0.31 & 0.19 & 0.10 & 0.03 & 0.01 & 0.05 & 0.09 & 0.17 & 0.26 & 0.35 & 0.38 & 0.49 & 0.28 \\
\hline Rosdo & 0.36 & 0.43 & 0.33 & 0.26 & 0.16 & 0.07 & 0.03 & 0.01 & 0.10 & 0.25 & 0.23 & 0.25 & 0.33 & 0.41 & 0.42 & 0.53 & 0.32 \\
\hline Rosup & 0.38 & \begin{tabular}{|l|}
0.45 \\
\end{tabular} & 0.36 & 0.29 & 0.19 & 0.13 & 0.15 & 0.08 & \begin{tabular}{|l|}
0.12 \\
\end{tabular} & 0.18 & 0.24 & 0.34 & 0.41 & 0.44 & 0.41 & 0.52 & 0.29 \\
\hline Roldo & 0.38 & 0.44 & 0.42 & 0.35 & 0.43 & 0.37 & 0.29 & 0.50 & 0.53 & 0.69 & 0.83 & 0.84 & 1.03 & 0.88 & 0.87 & 0.94 & 0.50 \\
\hline Rolup & 0.71 & 0.90 & 0.70 & 0.54 & 0.43 & 0.31 & 0.43 & 0.48 & 0.21 & 0.19 & 0.17 & 0.21 & 0.29 & 0.39 & 0.40 & 0.54 & 0.32 \\
\hline Shiftup & 0.49 & 0.67 & 0.70 & 0.47 & 0.34 & 0.26 & 0.13 & 0.15 & 0.18 & 0.15 & 0.17 & 0.19 & 0.27 & 0.38 & 0.42 & 0.60 & 0.33 \\
\hline Shiftdo & 0.38 & 0.45 & 0.31 & 0.24 & 0.14 & 0.08 & 0.07 & 0.08 & \begin{tabular}{|l|l|}
0.17 \\
\end{tabular} & 0.33 & 0.34 & 0.51 & 0.70 & 0.63 & 0.60 & 0.64 & 0.35 \\
\hline TS.Nochg & 0.75 & 0.93 & 0.77 & 0.60 & 0.37 & 0.39 & 0.33 & 0.30 & 0.35 & 0.52 & 0.60 & 0.88 & 1.00 & 1.28 & 1.24 & 1.09 & 0.58 \\
\hline TS.Pivclo & 0.39 & \begin{tabular}{|l|}
0.44 \\
\end{tabular} & 0.33 & 0.24 & 0.14 & 0.06 & 0.03 & 0.01 & 0.02 & 0.08 & 0.15 & 0.29 & 0.41 & 0.52 & 0.49 & 0.64 & 0.39 \\
\hline TS.Pivent & 0.40 & \begin{tabular}{|l|}
0.48 \\
\end{tabular} & 0.47 & 0.35 & 0.21 & 0.12 & 0.05 & 0.02 & 0.02 & 0.05 & 0.09 & 0.16 & 0.26 & 0.36 & 0.39 & 0.52 & 0.29 \\
\hline TS.Rosdo & 0.39 & 0.44 & 0.35 & 0.28 & 0.17 & 0.10 & 0.07 & 0.05 & 0.05 & 0.06 & 0.10 & 0.20 & 0.31 & 0.42 & 0.43 & 0.54 & 0.34 \\
\hline TS.Rosup & 0.45 & 0.49 & 0.43 & 0.31 & 0.21 & 0.12 & 0.09 & 0.05 & 0.05 & 0.08 & 0.12 & 0.21 & 0.30 & 0.39 & 0.43 & 0.61 & 0.37 \\
\hline TS.Roldo & 0.45 & 0.53 & 0.37 & 0.35 & 0.23 & 0.21 & 0.23 & 0.35 & 0.40 & 0.59 & 0.68 & 0.77 & 0.84 & 0.77 & 0.75 & 0.97 & 0.52 \\
\hline TS.Rolup & 0.76 & 0.82 & 0.60 & 0.51 & 0.32 & 0.19 & 0.12 & 0.07 & 0.04 & 0.08 & 0.13 & 0.29 & 0.51 & 0.63 & 0.60 & 0.79 & 0.48 \\
\hline TS.Shiftup & 0.44 & 0.52 & 0.52 & 0.39 & 0.30 & 0.18 & 0.09 & 0.09 & 0.06 & 0.08 & 0.11 & 0.22 & 0.32 & 0.47 & 0.49 & 0.66 & 0.36 \\
\hline TS.Shiftdo & 0.41 & 0.50 & 0.38 & 0.32 & 0.18 & 0.09 & 0.06 & 0.04 & 0.09 & 0.18 & 0.18 & 0.33 & 0.49 & 0.56 & 0.55 & 0.64 & 0.38 \\
\hline
\end{tabular}

Note: Quantile causality results for the null hypothesis that term spread, pattern changes, and interaction terms do not Granger cause excess stock returns; $*$ indicates rejection at the $5 \%$ significance level. 
Table 4b: Quantile Causality Results for UK Volatility (0.2 sd)

\begin{tabular}{|c|c|c|c|c|c|c|c|c|c|c|c|c|c|c|c|c|c|}
\hline & 0.10 & 0.15 & 0.20 & 0.25 & 0.30 & 0.35 & 0.40 & 0.45 & 0.50 & 0.55 & 0.60 & 0.65 & 0.70 & 0.75 & 0.80 & 0.85 & 0.90 \\
\hline TS & $2.12^{*}$ & $2.78^{*}$ & $3.22 *$ & $3.50^{*}$ & $3.74^{*}$ & $4.19 *$ & $4.38^{*}$ & $4.77^{*}$ & $4.87^{*}$ & $5.80^{*}$ & $5.75^{*}$ & $5.84^{*}$ & $5.74^{*}$ & $5.68^{*}$ & $5.15^{*}$ & $3.92 *$ & $2.89^{*}$ \\
\hline Nochg & 0.54 & 0.51 & 1.18 & 1.67 & 1.15 & 1.23 & 1.08 & 1.26 & 1.60 & $2.90 *$ & $2.56^{*}$ & $2.43^{*}$ & $3.36^{*}$ & 4.01* & $3.24^{*}$ & 1.20 & 1.22 \\
\hline Pivclo & 0.58 & 0.30 & 1.21 & $2.10^{*}$ & 1.37 & 1.25 & 0.77 & 0.72 & 1.40 & $2.51 *$ & $2.66^{*}$ & $2.57 *$ & $3.22 *$ & $4.81 *$ & $4.11 *$ & 1.48 & 1.13 \\
\hline Pivent & 0.64 & 0.27 & 0.96 & 1.71 & 1.12 & 0.90 & 0.60 & 0.60 & 1.11 & $2.36^{*}$ & $2.46^{*}$ & $2.38^{*}$ & $3.13 *$ & $4.53 *$ & $3.98^{*}$ & 1.50 & 1.23 \\
\hline Rosdo & 0.46 & 0.43 & 0.97 & 1.74 & 1.18 & 1.11 & 0.70 & 0.73 & 1.07 & $2.08^{*}$ & $2.10^{*}$ & $2.05^{*}$ & $2.63 *$ & $4.08^{*}$ & $3.55^{*}$ & 1.29 & 1.03 \\
\hline Rosup & 0.62 & 0.45 & 1.11 & $2.03^{*}$ & 1.41 & 1.30 & 1.11 & 1.14 & 1.62 & $2.62^{*}$ & $2.63^{*}$ & $2.56^{*}$ & $2.77^{*}$ & $4.01 *$ & $3.46^{*}$ & 1.17 & 0.92 \\
\hline Roldo & 0.37 & 0.28 & 1.19 & 1.65 & 1.18 & 1.15 & 0.73 & 0.75 & 1.59 & $2.54 *$ & $2.66^{*}$ & $2.16^{*}$ & $2.46^{*}$ & $4.20 *$ & $3.31 *$ & 1.24 & 1.10 \\
\hline Rolup & 0.34 & 0.27 & 1.48 & $2.38^{*}$ & 1.53 & 1.34 & 0.86 & 0.76 & 1.59 & $2.53^{*}$ & $2.65^{*}$ & $2.57^{*}$ & $3.09 *$ & $4.82^{*}$ & $4.57^{*}$ & 1.84 & 1.62 \\
\hline Shiftup & 0.33 & 0.21 & 1.12 & $1.98^{*}$ & 1.37 & 1.15 & 0.83 & 0.79 & 1.37 & $2.51^{*}$ & $2.71 *$ & $2.82^{*}$ & $3.81 *$ & $5.04 *$ & $4.15^{*}$ & 1.55 & 1.23 \\
\hline Shiftdo & 0.39 & 0.25 & 1.14 & $2.06^{*}$ & 1.23 & 1.08 & 0.75 & 0.75 & 1.36 & $2.61 *$ & $2.65^{*}$ & $2.41 *$ & $2.74 *$ & $4.32 *$ & $3.88^{*}$ & 1.41 & 1.10 \\
\hline TS.Nochg & 0.87 & 0.59 & 1.41 & 1.91 & 1.22 & 1.21 & 1.29 & 1.42 & 1.70 & $3.77^{*}$ & $3.84^{*}$ & $3.56^{*}$ & $5.30^{*}$ & $5.31^{*}$ & $3.99 *$ & 1.65 & 1.93 \\
\hline TS.Pivclo & 0.57 & 0.31 & 1.21 & $2.10^{*}$ & 1.38 & 1.26 & 0.78 & 0.73 & 1.40 & $2.50^{*}$ & $2.66^{*}$ & $2.57^{*}$ & $3.23 *$ & $4.81 *$ & $4.11 *$ & 1.49 & 1.13 \\
\hline TS.Pivent & 0.63 & 0.26 & 0.94 & 1.70 & 1.11 & 0.87 & 0.58 & 0.58 & 1.09 & $2.36^{*}$ & $2.45^{*}$ & $2.38^{*}$ & $3.13^{*}$ & $4.53 *$ & $3.98^{*}$ & 1.51 & 1.23 \\
\hline TS.Rosdo & 0.49 & 0.44 & 0.90 & 1.66 & 1.11 & 1.10 & 0.68 & 0.58 & 0.86 & 1.95 & 1.95 & 1.86 & $2.49 *$ & $3.90 *$ & $3.40^{*}$ & 1.19 & 0.96 \\
\hline TS.Rosup & 0.63 & 0.46 & 1.08 & $2.01 *$ & 1.42 & 1.30 & 1.05 & 1.06 & 1.53 & $2.38^{*}$ & $2.45^{*}$ & $2.47^{*}$ & $2.58^{*}$ & $3.79 *$ & $3.32 *$ & 1.09 & 0.82 \\
\hline TS.Roldo & 0.35 & 0.32 & 1.25 & 1.65 & 1.22 & 1.19 & 0.75 & 0.79 & 1.64 & $2.57^{*}$ & $2.71 *$ & $2.15^{*}$ & $2.37 *$ & $4.17^{*}$ & $3.21 *$ & 1.22 & 1.08 \\
\hline TS.Rolup & 0.33 & 0.22 & 1.47 & $2.47 *$ & 1.59 & 1.40 & 0.92 & 0.83 & 1.69 & $2.63^{*}$ & $2.74^{*}$ & $2.67^{*}$ & $3.18^{*}$ & $4.92^{*}$ & $4.67^{*}$ & 1.89 & 1.66 \\
\hline TS.Shiftup & 0.32 & 0.21 & 1.16 & $2.00^{*}$ & 1.40 & 1.17 & 0.89 & 0.84 & 1.43 & $2.57 *$ & $2.77^{*}$ & $2.86^{*}$ & $3.84^{*}$ & $5.07^{*}$ & $4.17^{*}$ & 1.56 & 1.23 \\
\hline TS.Shiftdo & 0.39 & 0.26 & 1.16 & $2.08^{*}$ & 1.24 & 1.10 & 0.77 & 0.78 & 1.38 & $2.62^{*}$ & $2.68^{*}$ & $2.42^{*}$ & $2.72^{*}$ & $4.31 *$ & $3.88^{*}$ & 1.42 & 1.09 \\
\hline
\end{tabular}

Note: Quantile causality results for the null hypothesis that term spread, pattern changes, and interaction terms do not Granger excess stock returns volatility; $*$ indicates rejection at the $5 \%$ significance level. 
Table 5a: Quantile Causality Results for UK Excess Returns, Sub-sample 1 (1753:08-1825:01)

\begin{tabular}{|c|c|c|c|c|c|c|c|c|c|c|c|c|c|c|c|c|c|}
\hline & 0.10 & 0.15 & 0.20 & 0.25 & 0.30 & 0.35 & 0.40 & 0.45 & 0.50 & 0.55 & 0.60 & 0.65 & 0.70 & 0.75 & 0.80 & 0.85 & 0.90 \\
\hline TS & 1.39 & 1.46 & 1.60 & 1.91 & 1.93 & 1.75 & 1.70 & 1.58 & 1.66 & 1.86 & $2.03^{*}$ & 1.95 & 1.75 & 1.90 & 1.42 & 1.49 & 1.33 \\
\hline Nochg & 1.03 & 0.59 & 0.52 & 0.50 & 0.74 & 0.73 & 1.09 & 1.39 & 1.61 & 1.05 & 1.17 & 1.63 & 1.83 & 1.47 & 0.84 & 0.98 & 0.97 \\
\hline Pivclo & 0.75 & \begin{tabular}{|l|}
0.43 \\
\end{tabular} & 0.41 & 0.50 & 0.58 & 0.34 & 0.55 & 0.59 & 0.70 & 0.46 & 0.72 & 0.84 & 0.53 & 0.68 & 0.57 & 0.61 & 0.92 \\
\hline Pivent & 0.89 & 0.52 & 0.48 & 0.61 & 0.64 & 0.40 & 0.63 & 0.62 & 0.68 & 0.42 & 0.58 & 0.70 & 0.39 & 0.55 & 0.48 & 0.53 & 0.93 \\
\hline Rosdo & 0.76 & 0.41 & 0.43 & 0.45 & 0.45 & 0.32 & 0.52 & 0.54 & 0.58 & 0.35 & 0.52 & 0.64 & 0.45 & 0.67 & 0.59 & 0.68 & 1.10 \\
\hline Rosup & 0.81 & 0.64 & 0.51 & 0.70 & 0.72 & 0.42 & 0.80 & 0.75 & 0.75 & 0.52 & 0.59 & 0.73 & 0.43 & 0.63 & 0.51 & 0.57 & 0.87 \\
\hline Roldo & 0.66 & 0.49 & 0.45 & 0.54 & 0.52 & 0.61 & 0.71 & 0.79 & 1.13 & 0.79 & 1.28 & 1.78 & 1.95 & $2.49 *$ & 1.67 & 1.70 & 1.42 \\
\hline Rolup & 0.65 & 0.39 & 0.46 & 0.45 & 0.57 & 0.49 & 0.68 & 0.77 & 0.89 & 0.65 & 0.91 & 0.94 & 0.49 & 0.79 & 0.55 & 0.64 & 0.79 \\
\hline Shiftup & 0.65 & 0.37 & 0.38 & 0.51 & 0.56 & 0.33 & 0.58 & 0.64 & 0.71 & 0.46 & 0.54 & 0.61 & 0.36 & 0.55 & 0.46 & 0.49 & 0.87 \\
\hline Shiftdo & 0.73 & 0.39 & 0.34 & 0.43 & 0.51 & 0.32 & 0.50 & 0.52 & 0.68 & 0.41 & 0.60 & 0.70 & 0.44 & 0.69 & 0.68 & 0.70 & 1.08 \\
\hline TS.Nochg & 1.48 & 0.85 & 0.70 & 0.65 & 1.00 & 0.94 & 1.32 & 1.71 & 1.87 & 1.34 & 1.41 & 1.67 & 1.57 & 1.06 & 0.60 & 0.60 & 0.79 \\
\hline TS.Pivclo & 0.76 & \begin{tabular}{|l|}
0.43 \\
\end{tabular} & 0.42 & 0.48 & 0.54 & 0.31 & 0.53 & 0.56 & \begin{tabular}{|l|}
0.67 \\
\end{tabular} & 0.42 & 0.69 & 0.81 & 0.51 & 0.67 & 0.57 & 0.62 & 0.92 \\
\hline TS.Pivent & 0.88 & 0.52 & 0.49 & 0.62 & 0.64 & 0.39 & 0.63 & 0.62 & 0.68 & 0.42 & 0.57 & 0.68 & 0.37 & 0.54 & 0.47 & 0.52 & 0.93 \\
\hline TS.Rosdo & 0.76 & 0.42 & 0.45 & 0.47 & 0.46 & 0.34 & 0.53 & 0.56 & 0.60 & 0.37 & 0.54 & 0.65 & 0.45 & 0.68 & 0.61 & 0.70 & 1.12 \\
\hline TS.Rosup & 0.81 & \begin{tabular}{|l|}
0.62 \\
\end{tabular} & 0.50 & 0.69 & 0.71 & 0.41 & 0.76 & 0.72 & \begin{tabular}{|l|}
0.73 \\
\end{tabular} & 0.50 & 0.58 & 0.71 & 0.41 & 0.62 & 0.51 & 0.57 & 0.87 \\
\hline TS.Roldo & 0.75 & 0.50 & 0.48 & 0.63 & 0.48 & 0.50 & 0.56 & 0.59 & 0.68 & 0.47 & 1.04 & 1.30 & 1.64 & $2.23^{*}$ & 1.81 & 1.74 & 1.63 \\
\hline TS.Rolup & 0.73 & 0.58 & 0.63 & 0.61 & 0.75 & 0.62 & 0.79 & 0.78 & 0.84 & 0.63 & 0.87 & 0.94 & 0.52 & 0.76 & 0.48 & 0.54 & 0.76 \\
\hline TS.Shiftup & 0.60 & 0.34 & 0.35 & 0.49 & 0.55 & 0.33 & 0.58 & 0.64 & 0.71 & 0.46 & 0.54 & 0.61 & 0.37 & 0.56 & 0.46 & 0.50 & 0.87 \\
\hline TS.Shiftdo & 0.72 & \begin{tabular}{|l|}
0.39 \\
\end{tabular} & 0.33 & 0.41 & 0.48 & 0.30 & 0.47 & 0.49 & \begin{tabular}{|l|}
0.63 \\
\end{tabular} & 0.39 & 0.57 & 0.69 & 0.45 & 0.70 & 0.69 & 0.71 & 1.10 \\
\hline
\end{tabular}

Note: Quantile causality results for the null hypothesis that term spread, pattern changes, and interaction terms do not Granger cause excess stock returns; * indicates rejection at the $5 \%$ significance level. 
Table 5b: Quantile Causality Results for UK Volatility, Sub-sample 1 (1753:08-1825:01)

\begin{tabular}{|c|c|c|c|c|c|c|c|c|c|c|c|c|c|c|c|c|c|}
\hline & 0.10 & 0.15 & 0.20 & 0.25 & 0.30 & 0.35 & 0.40 & 0.45 & 0.50 & 0.55 & 0.60 & 0.65 & 0.70 & 0.75 & 0.80 & 0.85 & 0.90 \\
\hline TS & $2.07 *$ & $2.72^{*}$ & $2.48^{*}$ & $3.04 *$ & $2.99 *$ & $3.54^{*}$ & $3.89^{*}$ & $3.83^{*}$ & $3.38^{*}$ & $3.62^{*}$ & $3.51 *$ & $3.34 *$ & $3.28^{*}$ & 3.12* & $3.06^{*}$ & $2.23^{*}$ & 1.83 \\
\hline Nochg & 0.45 & 0.17 & 0.20 & 0.21 & 0.20 & 0.28 & 0.82 & 0.97 & 1.46 & 1.83 & $2.63^{*}$ & $2.89^{*}$ & 1.68 & 1.08 & 0.48 & 1.18 & 1.11 \\
\hline Pivclo & 0.07 & 0.11 & 0.16 & 0.30 & 0.22 & 0.28 & 0.64 & 0.72 & 1.27 & 1.71 & $2.52^{*}$ & $2.88^{*}$ & 1.87 & 1.16 & 0.57 & 1.51 & 1.25 \\
\hline Pivent & 0.07 & 0.12 & 0.19 & 0.29 & 0.20 & 0.34 & 0.71 & 0.78 & 1.35 & 1.75 & $2.60^{*}$ & $2.82^{*}$ & 1.66 & 0.98 & 0.50 & 1.34 & 1.07 \\
\hline Rosdo & 0.11 & 0.14 & 0.23 & 0.23 & 0.18 & 0.26 & 0.59 & 0.61 & 1.15 & 1.51 & $2.23^{*}$ & $2.45^{*}$ & 1.60 & 1.09 & 0.45 & 1.27 & 1.10 \\
\hline Rosup & 0.08 & 0.12 & 0.19 & 0.26 & 0.19 & 0.25 & 0.63 & 0.80 & 1.39 & 1.93 & $2.67 *$ & 2.84* & 1.64 & 0.95 & 0.43 & 1.24 & 1.05 \\
\hline Roldo & 0.14 & 0.12 & 0.18 & 0.20 & 0.24 & 0.36 & 0.59 & 1.02 & 1.03 & 1.22 & $1.98^{*}$ & $2.28^{*}$ & 1.30 & 0.88 & 0.47 & 1.14 & 0.81 \\
\hline Rolup & 0.08 & 0.12 & 0.17 & 0.28 & 0.26 & 0.63 & 1.04 & 1.22 & 1.52 & 2.00 & $3.18^{*}$ & $3.66^{*}$ & $2.30 *$ & 1.53 & 0.53 & 1.50 & 1.20 \\
\hline Shiftup & 0.08 & 0.11 & 0.17 & 0.26 & 0.18 & 0.29 & 0.66 & 0.72 & 1.40 & 1.84 & $2.67^{*}$ & $2.89^{*}$ & 1.82 & 1.28 & 0.63 & 1.62 & 1.27 \\
\hline Shiftdo & 0.09 & 0.12 & 0.21 & 0.42 & 0.25 & 0.36 & 0.84 & 0.80 & 1.38 & 1.87 & $2.90^{*}$ & $3.27 *$ & $1.97 *$ & 1.19 & 0.53 & 1.35 & 1.15 \\
\hline TS.Nochg & 0.43 & 0.29 & 0.33 & 0.33 & 0.45 & 0.61 & 1.38 & 1.62 & $2.24^{*}$ & $2.61 *$ & $3.53^{*}$ & $3.65^{*}$ & $2.27^{*}$ & 1.52 & 0.75 & 1.26 & 1.41 \\
\hline TS.Pivclo & 0.07 & 0.11 & 0.16 & 0.31 & 0.23 & 0.30 & 0.66 & 0.68 & 1.23 & 1.67 & $2.48^{*}$ & $2.85^{*}$ & 1.84 & 1.14 & 0.56 & 1.50 & 1.24 \\
\hline TS.Pivent & 0.07 & 0.12 & 0.19 & 0.30 & 0.21 & 0.34 & 0.72 & 0.78 & 1.36 & 1.75 & $2.61 *$ & $2.82^{*}$ & 1.66 & 0.98 & 0.50 & 1.35 & 1.07 \\
\hline TS.Rosdo & 0.10 & 0.14 & 0.22 & 0.24 & 0.19 & 0.27 & 0.59 & 0.62 & 1.15 & 1.49 & $2.20^{*}$ & $2.41 *$ & 1.60 & 1.10 & 0.46 & 1.27 & 1.11 \\
\hline TS.Rosup & 0.08 & 0.12 & 0.18 & 0.27 & 0.20 & 0.25 & 0.63 & 0.80 & 1.40 & 1.93 & $2.68^{*}$ & $2.85^{*}$ & 1.64 & 0.94 & 0.44 & 1.24 & 1.05 \\
\hline TS.Roldo & 0.19 & 0.24 & 0.31 & 0.33 & 0.26 & 0.28 & 0.31 & 0.28 & 0.49 & 0.66 & 1.09 & 1.34 & 0.89 & 0.65 & 0.37 & 1.18 & 0.73 \\
\hline TS.Rolup & 0.17 & 0.23 & 0.28 & 0.39 & 0.37 & 0.67 & 1.10 & 1.27 & 1.56 & 2.06 & $3.21 *$ & $3.63^{*}$ & $2.32^{*}$ & 1.57 & 0.61 & 1.42 & 1.20 \\
\hline TS.Shiftup & 0.08 & 0.11 & 0.17 & 0.26 & 0.18 & 0.29 & 0.66 & 0.72 & 1.40 & 1.84 & $2.67^{*}$ & $2.88^{*}$ & 1.82 & 1.28 & 0.63 & 1.62 & 1.27 \\
\hline TS.Shiftdo & 0.10 & 0.12 & 0.21 & 0.41 & 0.25 & 0.36 & 0.84 & 0.81 & 1.39 & 1.88 & $2.92^{*}$ & $3.28^{*}$ & 1.99* & 1.21 & 0.54 & 1.36 & 1.16 \\
\hline
\end{tabular}

Note: Quantile causality results for the null hypothesis that term spread, pattern changes, and interaction terms do not Granger cause excess stock returns volatility; * indicates rejection at the $5 \%$ significance level. 
Table 6a: Quantile Causality Results for UK Excess Returns, Sub-sample 2 (1825:02-2017:02)

\begin{tabular}{|c|c|c|c|c|c|c|c|c|c|c|c|c|c|c|c|c|c|}
\hline & 0.10 & 0.15 & 0.20 & 0.25 & 0.30 & 0.35 & 0.40 & 0.45 & 0.50 & 0.55 & 0.60 & 0.65 & 0.70 & 0.75 & 0.80 & 0.85 & 0.90 \\
\hline TS & $4.48^{*}$ & $6.56^{*}$ & $6.26^{*}$ & $6.93^{*}$ & $5.32 *$ & $4.80^{*}$ & $3.95^{*}$ & $3.82 *$ & 5.55* & 5.04* & 5.31* & $6.54^{*}$ & $7.01^{*}$ & $6.68^{*}$ & 6.49* & 6.14* & $4.65^{*}$ \\
\hline Nochg & $3.17^{*}$ & $4.00^{*}$ & $3.63 *$ & $2.69^{*}$ & $2.47 *$ & 1.30 & 0.61 & 0.63 & 1.60 & $2.26^{*}$ & 2.94* & $4.20^{*}$ & $5.71^{*}$ & 7.44* & 7.11* & $5.87^{*}$ & $4.52^{*}$ \\
\hline Pivclo & $3.11 *$ & $4.32 *$ & $3.28 *$ & $2.81 *$ & $2.25^{*}$ & 1.33 & 0.81 & 0.35 & 0.46 & 1.39 & $2.05^{*}$ & $3.31 *$ & $5.02^{*}$ & $5.39 *$ & $5.48^{*}$ & $5.74 *$ & $4.17^{*}$ \\
\hline Pivent & $3.38^{*}$ & $4.83^{*}$ & 4.11* & $3.95^{*}$ & $2.82^{*}$ & 1.80 & 0.89 & 0.33 & 0.38 & 1.12 & 1.70 & $2.65^{*}$ & $4.15^{*}$ & $4.58^{*}$ & $4.60^{*}$ & $4.98^{*}$ & $4.23^{*}$ \\
\hline Rosdo & $2.63 *$ & $3.53^{*}$ & $2.69 *$ & $2.46^{*}$ & 1.93 & 1.27 & 0.82 & 0.47 & 0.54 & 1.14 & 1.87 & $3.03 *$ & $4.14 *$ & 4.59* & $4.83^{*}$ & $4.96^{*}$ & $4.09 *$ \\
\hline Rosup & $3.06^{*}$ & $4.10^{*}$ & $3.49 *$ & $3.34 *$ & $3.03^{*}$ & 1.84 & 1.01 & 0.63 & 0.54 & 1.07 & 1.48 & $2.24 *$ & $3.43^{*}$ & $4.00^{*}$ & 4.14* & $4.59 *$ & $3.68^{*}$ \\
\hline Roldo & $3.32 *$ & $4.26^{*}$ & $3.07 *$ & $2.62^{*}$ & 1.90 & $1.37 *$ & 1.31 & 1.62 & $3.02^{*}$ & $5.73^{*}$ & 6.44* & $6.85^{*}$ & $8.67 *$ & $7.76^{*}$ & 7.64* & $6.15^{*}$ & $5.08^{*}$ \\
\hline Rolup & $5.00^{*}$ & 6.99* & 5.71* & $5.77^{*}$ & $5.17 *$ & $3.83^{*}$ & $2.90^{*}$ & 1.43 & 0.97 & 1.32 & 1.87 & $2.69 *$ & $4.06^{*}$ & $4.56^{*}$ & 4.74* & $5.12^{*}$ & $3.88^{*}$ \\
\hline Shiftup & $2.78^{*}$ & $4.13^{*}$ & $3.21 *$ & $2.91 *$ & $2.49 *$ & $2.14^{*}$ & 1.41 & 1.03 & 1.16 & 1.39 & 1.90 & $2.73^{*}$ & $4.12^{*}$ & $4.40^{*}$ & $4.73^{*}$ & $5.21 *$ & $4.55^{*}$ \\
\hline Shiftdo & $3.35^{*}$ & $3.97 *$ & $2.94 *$ & $2.52^{*}$ & 1.99* & 1.00 & 0.62 & 0.42 & 0.70 & 1.92 & $2.21 *$ & $3.47 *$ & $4.60^{*}$ & $4.85^{*}$ & $4.40^{*}$ & $4.92^{*}$ & $4.01^{*}$ \\
\hline TS.Nochg & $3.71 *$ & $4.83^{*}$ & $4.29 *$ & $3.39 *$ & $3.07 *$ & 1.84 & 0.90 & 0.58 & 1.16 & 1.92 & $2.73^{*}$ & $3.96^{*}$ & $5.65^{*}$ & 6.64* & $6.36^{*}$ & $5.78^{*}$ & $4.51^{*}$ \\
\hline TS.Pivclo & $3.10^{*}$ & $4.38^{*}$ & $3.19 *$ & $2.74^{*}$ & $2.05^{*}$ & 1.21 & 0.73 & 0.31 & 0.52 & 1.55 & $2.26^{*}$ & $3.58^{*}$ & $5.26^{*}$ & $5.60^{*}$ & $5.62^{*}$ & $5.90^{*}$ & $4.30^{*}$ \\
\hline TS.Pivent & $3.44 *$ & $4.85^{*}$ & $4.08 *$ & $3.74^{*}$ & $2.78^{*}$ & 1.73 & 0.83 & 0.32 & 0.37 & 1.13 & 1.73 & $2.81 *$ & $4.35^{*}$ & $4.75^{*}$ & $4.70^{*}$ & 5.04* & $4.25^{*}$ \\
\hline TS.Rosdo & $2.72 *$ & $3.57 *$ & $2.44 *$ & $2.31 *$ & 1.66 & 1.04 & 0.80 & 0.49 & 0.64 & 1.28 & $2.01 *$ & $3.09 *$ & $4.19 *$ & $4.63^{*}$ & 5.04* & $5.15^{*}$ & $4.21 *$ \\
\hline TS.Rosup & $3.17^{*}$ & 4.31* & 3.79* & $3.64^{*}$ & $3.17^{*}$ & 1.87 & 1.10 & 0.65 & 0.52 & 1.03 & 1.40 & $2.11 *$ & $3.30^{*}$ & $4.00^{*}$ & $4.16^{*}$ & $4.62^{*}$ & $3.73^{*}$ \\
\hline TS.Roldo & $3.55^{*}$ & $4.49 *$ & $3.16^{*}$ & $2.70^{*}$ & 1.73 & 0.86 & 0.76 & 0.91 & 1.91 & $4.15^{*}$ & $5.10^{*}$ & $6.07 *$ & $7.87^{*}$ & 7.48* & $7.55^{*}$ & $6.26^{*}$ & $5.04^{*}$ \\
\hline TS.Rolup & $4.89 *$ & 6.41* & 4.99* & $5.02^{*}$ & $4.16^{*}$ & $2.90^{*}$ & $1.97^{*}$ & 0.88 & 0.68 & 1.32 & $1.97 *$ & $2.90^{*}$ & $4.28^{*}$ & $4.98^{*}$ & $5.16^{*}$ & $5.56^{*}$ & $4.17^{*}$ \\
\hline TS.Shiftup & $2.62^{*}$ & $3.89 *$ & $3.09 *$ & $2.91 *$ & $2.36^{*}$ & 1.85 & 1.20 & 0.74 & 0.70 & 1.17 & 1.87 & $2.86^{*}$ & $4.32^{*}$ & $4.71 *$ & 5.19* & $5.65^{*}$ & $4.92^{*}$ \\
\hline TS.Shiftdo & $3.35^{*}$ & $4.05^{*}$ & $3.07 *$ & $2.76^{*}$ & $2.19 *$ & 1.01 & 0.55 & 0.37 & 0.79 & 1.94 & $2.24^{*}$ & $3.48^{*}$ & $4.71^{*}$ & $5.15^{*}$ & 4.81* & $5.34^{*}$ & $4.43^{*}$ \\
\hline
\end{tabular}

Note: Quantile causality results for the null hypothesis that term spread, pattern changes, and interaction terms do not Granger cause excess stock returns; * indicates rejection at the $5 \%$ significance level. 
Table 6b: Quantile Causality Results for UK Volatility, Sub-sample 2 (1825:02-2017:02)

\begin{tabular}{|c|c|c|c|c|c|c|c|c|c|c|c|c|c|c|c|c|c|}
\hline & 0.10 & 0.15 & 0.20 & 0.25 & 0.30 & 0.35 & 0.40 & 0.45 & 0.50 & 0.55 & 0.60 & 0.65 & 0.70 & 0.75 & 0.80 & 0.85 & 0.90 \\
\hline TS & 1.53 & 1.83 & 1.76 & 1.99* & $2.03^{*}$ & $2.97^{*}$ & $3.38^{*}$ & 4.04* & $4.03^{*}$ & $4.45^{*}$ & $4.51 *$ & 4.74* & $3.98^{*}$ & 4.05* & $3.70^{*}$ & $2.85^{*}$ & 1.94 \\
\hline Nochg & 0.55 & 0.46 & 0.53 & 0.45 & 0.62 & 0.70 & 0.64 & 1.18 & 1.23 & $2.44 *$ & $3.30^{*}$ & $4.06^{*}$ & $4.39 *$ & 4.54* & $3.78^{*}$ & $2.45^{*}$ & 1.45 \\
\hline Pivclo & 0.50 & 0.57 & 0.43 & 0.43 & 0.36 & 0.48 & 0.52 & 0.59 & 0.64 & 1.51 & 1.81 & $2.05^{*}$ & $3.16^{*}$ & 3.41* & $3.05^{*}$ & 1.60 & 0.79 \\
\hline Pivent & 0.41 & 0.48 & 0.42 & 0.37 & 0.33 & 0.36 & 0.35 & 0.48 & 0.59 & 1.67 & 1.86 & 1.93 & 2.94* & $3.18^{*}$ & $3.14 *$ & 1.75 & 0.89 \\
\hline Rosdo & 1.08 & 1.39 & 1.80 & 1.78 & 1.41 & 1.46 & 1.51 & 0.82 & 1.01 & 1.51 & 1.68 & 1.95 & $2.63^{*}$ & $2.78^{*}$ & 2.54* & 1.37 & 0.85 \\
\hline Rosup & 0.85 & 0.69 & 0.61 & 0.85 & 0.81 & 0.86 & 0.77 & 0.67 & 0.62 & 1.40 & 1.62 & 1.78 & $2.51 *$ & $2.65^{*}$ & $2.45^{*}$ & 1.29 & 0.68 \\
\hline Roldo & 0.32 & 0.37 & 0.39 & 0.42 & 0.39 & 0.50 & 0.42 & 0.98 & 1.49 & $2.55^{*}$ & $2.71 *$ & $2.78^{*}$ & $4.00^{*}$ & 3.89* & $3.09 *$ & 1.74 & 1.01 \\
\hline Rolup & 0.36 & 0.43 & 0.34 & 0.38 & 0.40 & 0.56 & 0.66 & 1.02 & 1.08 & $2.12^{*}$ & $2.24 *$ & $2.81 *$ & 4.19* & 4.64* & $3.63^{*}$ & $2.65^{*}$ & 1.43 \\
\hline Shiftup & 0.59 & 0.79 & 0.64 & 0.89 & 1.03 & 1.13 & 1.37 & 1.26 & 1.36 & 1.87 & 1.93 & $1.96^{*}$ & $2.94^{*}$ & $3.18^{*}$ & $2.90^{*}$ & 1.65 & 1.01 \\
\hline Shiftdo & 0.44 & 0.44 & 0.29 & 0.27 & 0.29 & 0.31 & 0.28 & 0.45 & 0.58 & 1.23 & 1.40 & 1.63 & $2.43 *$ & $2.85^{*}$ & $2.72^{*}$ & 1.45 & 0.72 \\
\hline TS.Nochg & 0.42 & 0.33 & 0.26 & 0.26 & 0.32 & 0.44 & 0.55 & 1.17 & 1.38 & $2.71 *$ & $3.44 *$ & $4.07 *$ & $4.59 *$ & $4.85^{*}$ & $4.12^{*}$ & $2.78^{*}$ & 1.66 \\
\hline TS.Pivclo & 0.50 & \begin{tabular}{|l|}
0.59 \\
\end{tabular} & 0.43 & 0.44 & 0.37 & 0.49 & 0.53 & 0.59 & 0.65 & 1.52 & 1.82 & $2.06^{*}$ & $3.18^{*}$ & $3.42^{*}$ & $3.05^{*}$ & 1.62 & 0.78 \\
\hline TS.Pivent & 0.42 & 0.49 & 0.43 & 0.39 & 0.33 & 0.37 & 0.37 & 0.49 & 0.60 & 1.66 & 1.86 & $1.96^{*}$ & $2.97 *$ & $3.18^{*}$ & $3.17 *$ & 1.78 & 0.90 \\
\hline TS.Rosdo & 0.93 & 1.16 & 1.37 & 1.43 & 1.13 & 1.09 & 1.14 & 0.66 & 0.69 & 1.26 & 1.46 & 1.67 & $2.39 *$ & $2.46^{*}$ & $2.27 *$ & 1.21 & 0.77 \\
\hline TS.Rosup & 0.79 & 0.68 & 0.60 & 0.79 & 0.77 & 0.83 & 0.78 & 0.63 & 0.57 & 1.30 & 1.34 & 1.56 & $2.27^{*}$ & 2.39* & $2.28^{*}$ & 1.14 & 0.61 \\
\hline TS.Roldo & 0.26 & 0.35 & 0.16 & 0.16 & 0.17 & 0.22 & 0.22 & 0.85 & 1.24 & $2.37 *$ & $2.56^{*}$ & $2.73^{*}$ & $4.01 *$ & $3.91 *$ & $3.14^{*}$ & 1.80 & 1.06 \\
\hline TS.Rolup & 0.35 & 0.33 & 0.18 & 0.21 & 0.19 & 0.29 & 0.34 & 0.82 & 1.00 & $2.06^{*}$ & $2.22^{*}$ & $2.71^{*}$ & $3.99 *$ & $4.60^{*}$ & $3.68^{*}$ & $2.54^{*}$ & 1.32 \\
\hline TS.Shiftup & 0.60 & 0.82 & 0.70 & 0.89 & 0.93 & 0.99 & 1.17 & 1.05 & 1.05 & 1.70 & 1.85 & 1.89 & $2.97 *$ & $3.20^{*}$ & $2.92 *$ & 1.64 & 0.99 \\
\hline TS.Shiftdo & 0.46 & \begin{tabular}{|l|}
0.46 \\
\end{tabular} & 0.32 & 0.28 & 0.33 & 0.36 & 0.27 & 0.43 & 0.53 & 1.20 & 1.33 & 1.51 & $2.22 *$ & $2.74 *$ & 2.64* & 1.35 & 0.65 \\
\hline
\end{tabular}

Note: Quantile causality results for the null hypothesis that term spread, pattern changes, and interaction terms do not Granger cause excess stock returns volatility; * indicates rejection at the $5 \%$ significance level. 
Table 7a: Quantile Causality Results for US Excess Returns

\begin{tabular}{|c|c|c|c|c|c|c|c|c|c|c|c|c|c|c|c|c|c|}
\hline & 0.10 & 0.15 & 0.20 & 0.25 & 0.30 & 0.35 & 0.40 & 0.45 & 0.50 & 0.55 & 0.60 & 0.65 & 0.70 & 0.75 & 0.80 & 0.85 & 0.90 \\
\hline TS & 1.90 & $2.49 *$ & $3.07 *$ & $3.30^{*}$ & $3.02 *$ & $3.37^{*}$ & $3.89 *$ & $3.90^{*}$ & $4.22 *$ & $4.05^{*}$ & $3.70^{*}$ & $3.85^{*}$ & $4.00^{*}$ & $3.85^{*}$ & $3.87^{*}$ & $3.00^{*}$ & $2.16^{*}$ \\
\hline Nochg & 0.78 & 1.50 & 1.63 & 1.38 & 1.50 & 1.87 & 1.87 & 1.88 & 2.11* & 1.65 & 1.51 & 1.54 & 1.57 & 1.28 & 1.55 & 1.60 & 1.55 \\
\hline Pivclo & 0.62 & 1.01 & 1.37 & 0.84 & 0.80 & 0.97 & 1.47 & 1.46 & 1.74 & 1.25 & 1.29 & 1.25 & 1.33 & 1.22 & 1.53 & 1.16 & 0.96 \\
\hline Pivent & 0.78 & 1.13 & 1.48 & 1.11 & 1.09 & 1.25 & 1.65 & 1.75 & 1.81 & 1.35 & 1.24 & 1.23 & 1.31 & 1.21 & 1.53 & 1.13 & 0.95 \\
\hline Rosdo & 0.66 & 1.02 & 1.46 & 1.29 & 1.28 & 1.41 & 1.63 & 1.58 & $2.05^{*}$ & 1.50 & 1.41 & 1.33 & 1.23 & 0.99 & 1.29 & 0.99 & 0.96 \\
\hline Rosup & 0.76 & 1.13 & 1.52 & 0.98 & 1.15 & 1.45 & 1.80 & 1.86 & 1.99* & 1.83 & 1.87 & 1.69 & 1.64 & 1.47 & 1.60 & 1.21 & 0.95 \\
\hline Roldo & 0.98 & 0.94 & 1.16 & 0.76 & 0.77 & 1.04 & 1.57 & 1.64 & $2.05^{*}$ & 1.52 & 1.48 & 1.35 & 1.27 & 1.31 & 1.28 & 0.92 & 0.82 \\
\hline Rolup & 0.64 & 1.03 & 1.36 & 1.15 & 1.17 & 1.30 & 1.70 & 1.66 & 1.78 & 1.13 & 1.23 & 1.32 & 1.61 & 1.65 & 1.75 & 1.04 & 0.95 \\
\hline Shiftup & 0.77 & 1.31 & 1.45 & 1.13 & 1.07 & 1.27 & 1.73 & 1.43 & 1.67 & 1.24 & 1.20 & 1.34 & 1.31 & 1.37 & 1.48 & 1.01 & 0.99 \\
\hline Shiftdo & 0.73 & 1.40 & 1.67 & 1.34 & 1.23 & 1.42 & $2.00^{*}$ & 1.74 & $2.20^{*}$ & 1.79 & 1.80 & 1.89 & 1.85 & 1.65 & 1.70 & 1.23 & 1.22 \\
\hline TS.Nochg & 0.59 & 1.30 & 1.63 & 1.49 & 1.69 & $2.01^{*}$ & 1.93 & $2.06^{*}$ & 2.31* & 1.64 & 1.62 & 1.54 & 1.91 & 1.47 & 1.80 & 1.91 & 1.81 \\
\hline TS.Pivclo & 0.62 & 1.01 & 1.37 & 0.84 & 0.79 & 0.96 & 1.47 & 1.47 & 1.74 & 1.25 & 1.29 & 1.24 & 1.33 & 1.22 & 1.53 & 1.16 & 0.96 \\
\hline TS.Pivent & 0.80 & 1.14 & 1.50 & 1.13 & 1.11 & 1.27 & 1.67 & 1.76 & 1.81 & 1.35 & 1.23 & 1.24 & 1.32 & 1.22 & 1.55 & 1.14 & 0.95 \\
\hline TS.Rosdo & 0.68 & 0.99 & 1.54 & 1.16 & 1.10 & 1.18 & 1.49 & 1.51 & 1.97 & 1.49 & 1.36 & 1.23 & 1.09 & 0.91 & 1.33 & 1.07 & 0.96 \\
\hline TS.Rosup & 0.80 & 1.16 & 1.61 & 1.00 & 1.23 & 1.49 & 1.91 & 1.95 & 2.10 & 1.90 & 1.85 & 1.69 & 1.59 & 1.33 & 1.56 & 1.19 & 0.94 \\
\hline TS.Roldo & 0.93 & 0.89 & 1.13 & 0.73 & 0.75 & 1.03 & 1.56 & 1.61 & 1.97 & 1.44 & 1.40 & 1.36 & 1.25 & 1.25 & 1.33 & 0.93 & 0.86 \\
\hline TS.Rolup & 0.67 & 1.05 & 1.33 & 1.10 & 1.13 & 1.25 & 1.64 & 1.60 & 1.76 & 1.19 & 1.27 & 1.41 & 1.67 & 1.71 & 1.83 & 1.07 & 0.93 \\
\hline TS.Shiftup & 0.81 & 1.30 & 1.47 & 1.15 & 1.06 & 1.21 & 1.68 & 1.38 & 1.58 & 1.12 & 1.13 & 1.20 & 1.24 & 1.23 & 1.39 & 1.00 & 0.94 \\
\hline TS.Shiftdo & 0.72 & 1.38 & 1.63 & 1.26 & 1.19 & 1.38 & $1.96^{*}$ & 1.76 & 2.19* & 1.77 & 1.75 & 1.82 & 1.83 & 1.63 & 1.70 & 1.25 & 1.25 \\
\hline
\end{tabular}

Note: Quantile causality results for the null hypothesis that term spread, pattern changes, and interaction terms do not Granger cause excess stock returns; $*$ indicates rejection at the $5 \%$ significance level. 
Table 7b: Quantile Causality Results for US Volatility

\begin{tabular}{|c|c|c|c|c|c|c|c|c|c|c|c|c|c|c|c|c|c|}
\hline & 0.10 & 0.15 & 0.20 & 0.25 & 0.30 & 0.35 & 0.40 & 0.45 & 0.50 & 0.55 & 0.60 & 0.65 & 0.70 & 0.75 & 0.80 & 0.85 & 0.90 \\
\hline TS & $2.13^{*}$ & $2.45^{*}$ & $2.48^{*}$ & $2.51 *$ & $3.31 *$ & $3.49 *$ & $3.47^{*}$ & $3.65^{*}$ & $4.48^{*}$ & $4.29 *$ & $4.33^{*}$ & $3.99 *$ & $3.66^{*}$ & $2.81^{*}$ & 2.81* & $2.85^{*}$ & $2.25^{*}$ \\
\hline Nochg & 0.29 & 0.42 & 0.41 & 0.63 & 0.76 & 0.72 & 1.09 & 1.07 & 1.09 & 1.32 & 1.36 & 1.07 & 1.26 & 0.82 & 0.86 & 0.59 & 0.43 \\
\hline Pivclo & 0.24 & 0.09 & 0.17 & 0.19 & 0.19 & 0.25 & 0.46 & 0.43 & 0.73 & 1.17 & 1.32 & 1.05 & 1.38 & 0.95 & 0.65 & 0.22 & 0.15 \\
\hline Pivent & 0.35 & 0.12 & 0.15 & 0.16 & 0.14 & 0.30 & 0.71 & 0.64 & 0.90 & 1.39 & 1.52 & 1.19 & 1.47 & 1.03 & 0.76 & 0.26 & 0.19 \\
\hline Rosdo & 0.27 & 0.19 & 0.22 & 0.23 & 0.21 & 0.27 & 0.51 & 0.53 & 0.80 & 1.34 & 1.25 & 1.06 & 1.32 & 0.90 & 0.64 & 0.38 & 0.18 \\
\hline Rosup & 0.29 & 0.13 & 0.12 & 0.14 & 0.14 & 0.24 & 0.70 & 0.63 & 0.91 & 1.21 & 1.60 & 1.22 & 1.43 & 0.99 & 0.56 & 0.23 & 0.16 \\
\hline Roldo & 0.22 & 0.13 & 0.22 & 0.22 & 0.32 & 0.36 & 0.45 & 0.44 & 0.81 & 1.03 & 1.25 & 1.01 & 1.41 & 1.17 & 0.76 & 0.31 & 0.20 \\
\hline Rolup & 0.27 & 0.14 & 0.18 & 0.13 & 0.11 & 0.23 & 0.48 & 0.40 & 0.83 & 1.27 & 1.54 & 1.05 & 1.46 & 1.05 & 0.70 & 0.26 & 0.19 \\
\hline Shiftup & 0.41 & 0.18 & 0.19 & 0.20 & 0.17 & 0.29 & 0.69 & 0.69 & 1.07 & 1.33 & 1.51 & 1.17 & 1.41 & 1.05 & 0.69 & 0.28 & 0.16 \\
\hline Shiftdo & 0.28 & 0.10 & 0.13 & 0.12 & 0.11 & 0.22 & 0.42 & 0.52 & 0.82 & 1.24 & 1.42 & 1.02 & 1.43 & 0.97 & 0.68 & 0.29 & 0.17 \\
\hline TS.Nochg & 0.40 & 0.48 & 0.41 & 0.56 & 0.69 & 0.66 & 0.99 & 0.86 & 0.72 & 1.09 & 1.08 & 0.90 & 1.11 & 0.75 & 0.89 & 0.63 & 0.55 \\
\hline TS.Pivclo & 0.24 & 0.09 & 0.16 & 0.18 & 0.17 & 0.24 & 0.46 & 0.43 & 0.74 & 1.17 & 1.33 & 1.06 & 1.38 & 0.96 & 0.65 & 0.22 & 0.15 \\
\hline TS.Pivent & 0.35 & 0.12 & 0.16 & 0.17 & 0.14 & 0.31 & 0.70 & 0.64 & 0.91 & 1.40 & 1.53 & 1.21 & 1.48 & 1.04 & 0.77 & 0.26 & 0.20 \\
\hline TS.Rosdo & 0.27 & 0.19 & 0.23 & 0.23 & 0.21 & 0.29 & 0.56 & 0.55 & 0.88 & 1.43 & 1.36 & 1.12 & 1.39 & 0.97 & 0.71 & 0.42 & 0.25 \\
\hline TS.Rosup & 0.33 & 0.17 & 0.15 & 0.20 & 0.21 & 0.30 & 0.76 & 0.67 & 0.94 & 1.24 & 1.46 & 1.20 & 1.42 & 0.98 & 0.59 & 0.26 & 0.20 \\
\hline TS.Roldo & 0.24 & 0.15 & 0.25 & 0.23 & 0.28 & 0.34 & 0.41 & 0.48 & 0.85 & 1.02 & 1.23 & 1.04 & 1.43 & 1.20 & 0.81 & 0.35 & 0.21 \\
\hline TS.Rolup & 0.29 & 0.16 & 0.20 & 0.16 & 0.13 & 0.26 & 0.50 & 0.42 & 0.80 & 1.17 & 1.44 & 1.04 & 1.51 & 1.09 & 0.70 & 0.25 & 0.18 \\
\hline TS.Shiftup & 0.43 & 0.19 & 0.18 & 0.23 & 0.19 & 0.33 & 0.76 & 0.75 & 1.12 & 1.42 & 1.61 & 1.28 & 1.51 & 1.10 & 0.71 & 0.29 & 0.16 \\
\hline TS.Shiftdo & 0.30 & 0.12 & 0.16 & 0.14 & 0.14 & 0.23 & 0.41 & 0.54 & 0.84 & 1.25 & 1.43 & 1.04 & 1.46 & 1.01 & 0.71 & 0.31 & 0.18 \\
\hline
\end{tabular}

Note: Quantile causality results for the null hypothesis that term spread, pattern changes, and interaction terms do not Granger cause excess stock returns volatility; $*$ indicates rejection at the 5\% significance level. 
Table 8a: Quantile Causality Results for SA Excess Returns

\begin{tabular}{|c|c|c|c|c|c|c|c|c|c|c|c|c|c|c|c|c|c|}
\hline & 0.10 & 0.15 & 0.20 & 0.25 & 0.30 & 0.35 & 0.40 & 0.45 & 0.50 & 0.55 & 0.60 & 0.65 & 0.70 & 0.75 & 0.80 & 0.85 & 0.90 \\
\hline TS & $2.89 *$ & 4.65* & 5.74* & 5.44* & $4.92 *$ & $4.52^{*}$ & $4.37 *$ & $5.13^{*}$ & 5.96* & $5.75^{*}$ & $5.35^{*}$ & $4.98^{*}$ & $4.74 *$ & $4.72^{*}$ & $3.92 *$ & $3.33^{*}$ & $2.94^{*}$ \\
\hline Nochg & 1.29 & 1.15 & 1.70 & 1.55 & 1.81 & 1.65 & 1.76 & $2.61 *$ & $3.36^{*}$ & $3.75^{*}$ & $3.20^{*}$ & $2.92^{*}$ & $2.93^{*}$ & 2.84* & $2.33^{*}$ & $2.08^{*}$ & 1.66 \\
\hline Pivclo & 1.07 & 1.04 & 1.45 & 1.25 & 1.57 & 1.52 & 1.55 & $2.24 *$ & $3.25^{*}$ & $3.44^{*}$ & $3.21 *$ & $2.76^{*}$ & $2.52^{*}$ & $2.07 *$ & 1.64 & 1.37 & 1.64 \\
\hline Pivent & 1.09 & 1.01 & 1.40 & 1.16 & 1.38 & 1.35 & 1.46 & $2.20^{*}$ & $3.25^{*}$ & $3.50^{*}$ & $3.31 *$ & $2.90^{*}$ & $2.74^{*}$ & $2.30^{*}$ & 1.94 & 1.64 & 1.86 \\
\hline Rosdo & 1.12 & 1.03 & 1.53 & 1.34 & 1.63 & 1.76 & 1.62 & 2.54* & $3.70^{*}$ & $4.11 *$ & $3.95^{*}$ & $3.65^{*}$ & $3.34 *$ & $2.64 *$ & $2.24 *$ & 1.90 & 1.80 \\
\hline Rosup & 1.05 & 0.89 & 1.44 & 1.29 & 1.60 & 1.50 & 1.70 & $1.97 *$ & $3.16^{*}$ & $3.30^{*}$ & $2.94 *$ & $2.45^{*}$ & $2.48^{*}$ & 1.95 & 1.73 & 1.26 & 1.53 \\
\hline Roldo & 1.05 & 0.90 & 1.22 & 1.12 & 1.31 & 1.37 & 1.62 & $2.28^{*}$ & $3.28^{*}$ & $3.62^{*}$ & $3.64^{*}$ & $3.30^{*}$ & $3.06^{*}$ & $2.58^{*}$ & $2.01 *$ & 1.86 & 1.77 \\
\hline Rolup & 1.30 & 1.94 & $2.85^{*}$ & $2.87^{*}$ & $2.97 *$ & $2.35^{*}$ & $2.03^{*}$ & 3.01* & $3.35^{*}$ & $3.60^{*}$ & $3.23^{*}$ & $2.91 *$ & $2.51^{*}$ & $2.40^{*}$ & $2.05^{*}$ & 1.78 & 1.87 \\
\hline Shiftup & 1.04 & 1.07 & 1.48 & 1.39 & 1.53 & 1.44 & 1.58 & $2.30^{*}$ & $3.41 *$ & $3.85^{*}$ & $3.38^{*}$ & $2.59^{*}$ & $2.39^{*}$ & $1.96^{*}$ & 1.52 & 1.28 & 1.50 \\
\hline Shiftdo & 1.04 & 1.09 & 1.60 & 1.27 & 1.39 & 1.37 & 1.40 & $2.06^{*}$ & $3.19 *$ & $3.36^{*}$ & $3.12^{*}$ & $2.66^{*}$ & $2.52^{*}$ & $2.10^{*}$ & 1.80 & 1.48 & 1.78 \\
\hline TS.Nochg & 1.72 & 1.54 & 1.84 & 1.64 & 1.94 & 1.91 & $2.12^{*}$ & $3.18^{*}$ & $3.79 *$ & $3.52^{*}$ & $2.88^{*}$ & $2.49 *$ & $2.41^{*}$ & $2.42^{*}$ & $2.00^{*}$ & 1.51 & 1.43 \\
\hline TS.Pivclo & 1.07 & 1.04 & 1.45 & 1.25 & 1.57 & 1.52 & 1.56 & $2.24^{*}$ & $3.26^{*}$ & $3.44^{*}$ & $3.21 *$ & $2.76^{*}$ & $2.52^{*}$ & $2.07 *$ & 1.64 & 1.36 & 1.64 \\
\hline TS.Pivent & 1.09 & 1.01 & 1.40 & 1.16 & 1.37 & 1.35 & 1.45 & $2.18^{*}$ & $3.24 *$ & $3.48^{*}$ & $3.31 *$ & $2.90^{*}$ & $2.73^{*}$ & $2.29 *$ & 1.93 & 1.61 & 1.85 \\
\hline TS.Rosdo & 1.12 & 1.03 & 1.53 & 1.34 & 1.63 & 1.76 & 1.62 & $2.54 *$ & $3.70^{*}$ & $4.11 *$ & $3.95^{*}$ & $3.65^{*}$ & $3.34^{*}$ & 2.64* & $2.24^{*}$ & 1.90 & 1.80 \\
\hline TS.Rosup & 1.05 & 0.89 & 1.44 & 1.29 & 1.60 & 1.50 & 1.70 & $1.97 *$ & $3.16^{*}$ & $3.30^{*}$ & $2.94^{*}$ & $2.45^{*}$ & $2.48^{*}$ & 1.95 & 1.73 & 1.26 & 1.53 \\
\hline TS.Roldo & 1.05 & 0.90 & 1.22 & 1.12 & 1.31 & 1.37 & 1.62 & $2.28^{*}$ & $3.28^{*}$ & $3.62^{*}$ & 3.64* & $3.30^{*}$ & $3.06^{*}$ & $2.58^{*}$ & $2.01 *$ & 1.86 & 1.77 \\
\hline TS.Rolup & 1.30 & 1.94 & $2.85^{*}$ & $2.87^{*}$ & $2.97 *$ & $2.35^{*}$ & $2.03^{*}$ & $3.01 *$ & $3.35^{*}$ & $3.60^{*}$ & $3.23^{*}$ & $2.91 *$ & $2.51 *$ & $2.40^{*}$ & $2.05^{*}$ & 1.78 & 1.87 \\
\hline TS.Shiftup & 1.04 & 1.07 & 1.48 & 1.39 & 1.53 & 1.44 & 1.58 & $2.30^{*}$ & $3.41 *$ & $3.85^{*}$ & $3.38^{*}$ & $2.59 *$ & $2.39 *$ & $1.96^{*}$ & 1.52 & 1.28 & 1.50 \\
\hline TS.Shiftdo & 1.04 & 1.09 & 1.60 & 1.27 & 1.39 & 1.37 & 1.40 & $2.06^{*}$ & $3.19^{*}$ & $3.36^{*}$ & $3.12^{*}$ & $2.66^{*}$ & $2.52^{*}$ & $2.10^{*}$ & 1.80 & 1.48 & 1.78 \\
\hline
\end{tabular}

Note: Quantile causality results for the null hypothesis that term spread, pattern changes, and interaction terms do not Granger cause excess stock returns; * indicates rejection at the $5 \%$ significance level. 
Table 8b: Quantile Causality Results for SA Volatility

\begin{tabular}{|c|c|c|c|c|c|c|c|c|c|c|c|c|c|c|c|c|c|}
\hline & 0.10 & 0.15 & 0.20 & 0.25 & 0.30 & 0.35 & 0.40 & 0.45 & 0.50 & 0.55 & 0.60 & 0.65 & 0.70 & 0.75 & 0.80 & 0.85 & 0.90 \\
\hline TS & 1.70 & 1.99* & $2.71 *$ & $2.84 *$ & $4.20 *$ & $4.67^{*}$ & $6.06^{*}$ & $5.11^{*}$ & $4.71^{*}$ & $4.41 *$ & $5.22 *$ & $5.46^{*}$ & $4.97 *$ & $3.86^{*}$ & $3.59 *$ & $2.93^{*}$ & $2.48^{*}$ \\
\hline Nochg & 1.33 & $2.46^{*}$ & 1.73 & $2.06^{*}$ & $2.43^{*}$ & $2.28^{*}$ & $2.40^{*}$ & $2.23^{*}$ & $2.19^{*}$ & 1.67 & 1.79 & $2.14^{*}$ & $2.00^{*}$ & 1.09 & 1.05 & 0.58 & 0.35 \\
\hline Pivclo & 0.20 & 0.33 & 0.51 & 0.43 & 0.65 & 0.57 & 0.75 & 0.69 & 0.32 & 0.30 & 0.28 & 0.28 & 0.25 & 0.23 & 0.26 & 0.28 & 0.29 \\
\hline Pivent & 0.21 & 0.35 & 0.55 & 0.45 & 0.64 & 0.60 & 0.80 & 0.73 & 0.33 & 0.33 & 0.31 & 0.38 & 0.34 & 0.34 & 0.43 & 0.46 & 0.42 \\
\hline Rosdo & 0.39 & 0.58 & 0.86 & 0.66 & 0.82 & 0.91 & 1.06 & 1.13 & 0.61 & 0.48 & 0.46 & 0.47 & 0.45 & 0.41 & 0.26 & 0.37 & 0.27 \\
\hline Rosup & 0.26 & 0.35 & 0.36 & 0.41 & 0.55 & 0.49 & 0.59 & 0.61 & 0.37 & 0.44 & 0.41 & 0.37 & 0.32 & 0.24 & 0.25 & 0.27 & 0.31 \\
\hline Roldo & 0.29 & 0.49 & 0.61 & 0.38 & 0.65 & 0.57 & 0.63 & 0.56 & 0.28 & 0.31 & 0.29 & 0.25 & 0.25 & 0.27 & 0.52 & 0.35 & 0.36 \\
\hline Rolup & 0.19 & 0.34 & 0.59 & 0.45 & 0.82 & 1.12 & 1.46 & 1.05 & 0.58 & 0.54 & 0.52 & 0.76 & 0.64 & 0.43 & 0.31 & 0.38 & 0.28 \\
\hline Shiftup & 0.30 & 0.50 & 0.48 & 0.40 & 0.56 & 0.50 & 0.63 & 0.53 & 0.26 & 0.29 & 0.28 & 0.26 & 0.27 & 0.27 & 0.27 & 0.30 & 0.39 \\
\hline Shiftdo & 0.26 & 0.28 & 0.51 & 0.41 & 0.62 & 0.58 & 0.75 & 0.71 & 0.26 & 0.27 & 0.26 & 0.37 & 0.45 & 0.31 & 0.34 & 0.50 & 0.30 \\
\hline TS.Nochg & 1.02 & 1.82 & 1.48 & $2.29 *$ & $2.66^{*}$ & $2.40^{*}$ & $2.41 *$ & $2.19 *$ & $2.53^{*}$ & $2.15^{*}$ & $2.40^{*}$ & $2.26^{*}$ & $2.04 *$ & 1.31 & 1.15 & 0.77 & 0.57 \\
\hline TS.Pivclo & 0.20 & 0.33 & 0.51 & 0.43 & 0.65 & 0.57 & 0.75 & 0.69 & 0.31 & 0.30 & 0.28 & 0.28 & 0.25 & 0.24 & 0.27 & 0.28 & 0.29 \\
\hline TS.Pivent & 0.21 & 0.35 & 0.55 & 0.44 & 0.65 & 0.60 & 0.80 & 0.73 & 0.32 & 0.32 & 0.29 & 0.36 & 0.33 & 0.32 & 0.41 & 0.45 & 0.42 \\
\hline TS.Rosdo & 0.39 & 0.58 & 0.86 & 0.66 & 0.82 & 0.91 & 1.06 & 1.13 & 0.61 & 0.48 & 0.46 & 0.47 & 0.45 & 0.41 & 0.26 & 0.37 & 0.27 \\
\hline TS.Rosup & 0.26 & 0.35 & 0.36 & 0.41 & 0.55 & 0.49 & 0.59 & 0.61 & 0.37 & 0.44 & 0.41 & 0.37 & 0.32 & 0.24 & 0.25 & 0.27 & 0.31 \\
\hline TS.Roldo & 0.29 & 0.49 & 0.61 & 0.38 & 0.65 & 0.57 & 0.63 & 0.56 & 0.28 & 0.31 & 0.29 & 0.25 & 0.25 & 0.27 & 0.52 & 0.35 & 0.36 \\
\hline TS.Rolup & 0.19 & 0.34 & 0.59 & 0.45 & 0.82 & 1.12 & 1.46 & 1.05 & 0.58 & 0.54 & 0.52 & 0.76 & 0.64 & 0.43 & 0.31 & 0.38 & 0.28 \\
\hline TS.Shiftup & 0.30 & 0.50 & 0.48 & 0.40 & 0.56 & 0.50 & 0.63 & 0.53 & 0.26 & 0.29 & 0.28 & 0.26 & 0.27 & 0.27 & 0.27 & 0.30 & 0.39 \\
\hline TS.Shiftdo & 0.26 & 0.28 & 0.51 & 0.41 & 0.62 & 0.58 & 0.75 & 0.71 & 0.26 & 0.27 & 0.26 & 0.37 & 0.45 & 0.31 & 0.34 & 0.50 & 0.30 \\
\hline
\end{tabular}

Note: Quantile causality results for the null hypothesis that term spread, pattern changes, and interaction terms do not Granger cause excess stock returns volatility; ${ }^{*}$ indicates rejection at the $5 \%$ significance level. 
Appendix:

Table A1. Summary Statistics:

\begin{tabular}{|c|c|c|c|c|c|c|}
\cline { 2 - 7 } \multicolumn{1}{c|}{} & \multicolumn{7}{c|}{ Variable } \\
\hline Statistic & $\begin{array}{c}\text { Excess } \\
\text { Returns_UK }\end{array}$ & $\begin{array}{c}\text { Excess } \\
\text { Returns_US }\end{array}$ & $\begin{array}{c}\text { Excess } \\
\text { Returns_SA }\end{array}$ & Volatility_UK & Volatility_US & Volatility_SA \\
\hline Mean & -0.0019 & 0.0016 & 0.0010 & 0.0013 & 0.0017 & 0.0024 \\
\hline Median & -0.0015 & 0.0038 & 0.0043 & 0.0002 & 0.0005 & 0.0006 \\
\hline Maximum & 0.5325 & 0.4073 & 0.1619 & 0.2836 & 0.1659 & 0.0958 \\
\hline Minimum & -0.3177 & -0.3112 & -0.3096 & 0.0000 & 0.0000 & 0.0000 \\
\hline Std. Dev. & 0.0354 & 0.0407 & 0.0486 & 0.0070 & 0.0060 & 0.0056 \\
\hline Skewness & 1.0527 & -0.4211 & -0.9211 & 27.5585 & 16.3830 & 7.5446 \\
\hline Kurtosis & 32.2115 & 14.4096 & 6.7438 & 981.3459 & 371.2495 & 94.8871 \\
\hline Jarque-Bera & 113043.2000 & 9560.3130 & 706.5248 & 127000000.0000 & 9983431.0000 & 351895.1000 \\
\hline p-value & 0.0000 & 0.0000 & 0.0000 & 0.0000 & 0.0000 & 0.0000 \\
\hline Observations & 3163 & 1753 & 974 & 3163 & 1753 & 974 \\
\hline
\end{tabular}

Note: Std. Dev. symbolizes the Standard Deviation; $p$-value corresponds to the null of normality based on the Jarque-Bera test. 